Portland State University

PDXScholar

7-1-1993

\title{
The Culture of an Alternative Education Program: A Participant Observational Study
}

Dian Dee Connett

Portland State University

Follow this and additional works at: https://pdxscholar.library.pdx.edu/open_access_etds

Part of the Other Education Commons

Let us know how access to this document benefits you.

\section{Recommended Citation}

Connett, Dian Dee, "The Culture of an Alternative Education Program: A Participant Observational Study" (1993). Dissertations and Theses. Paper 1201.

https://doi.org/10.15760/etd.1200

This Dissertation is brought to you for free and open access. It has been accepted for inclusion in Dissertations and Theses by an authorized administrator of PDXScholar. Please contact us if we can make this document more accessible: pdxscholar@pdx.edu. 
THE CULTURE OF AN ALTERNATIVE EDUCATION PROGRAM:

A PARTICIPANT OBSERVATIONAL STUDY

by

DIAN DEE CONNETT

A dissertation submitted in partial fulfillment of the requirements for the degree of

DOCTOR OF EDUCATION in

COMMUNITY COLLEGE

EDUCATION

Portland State University

Q1993 


\section{TO THE OFFICE OF GRADUATE STUDIES:}

The members of the Committee approve the dissertation of Dian Dee Connett presented July 1, 1993.

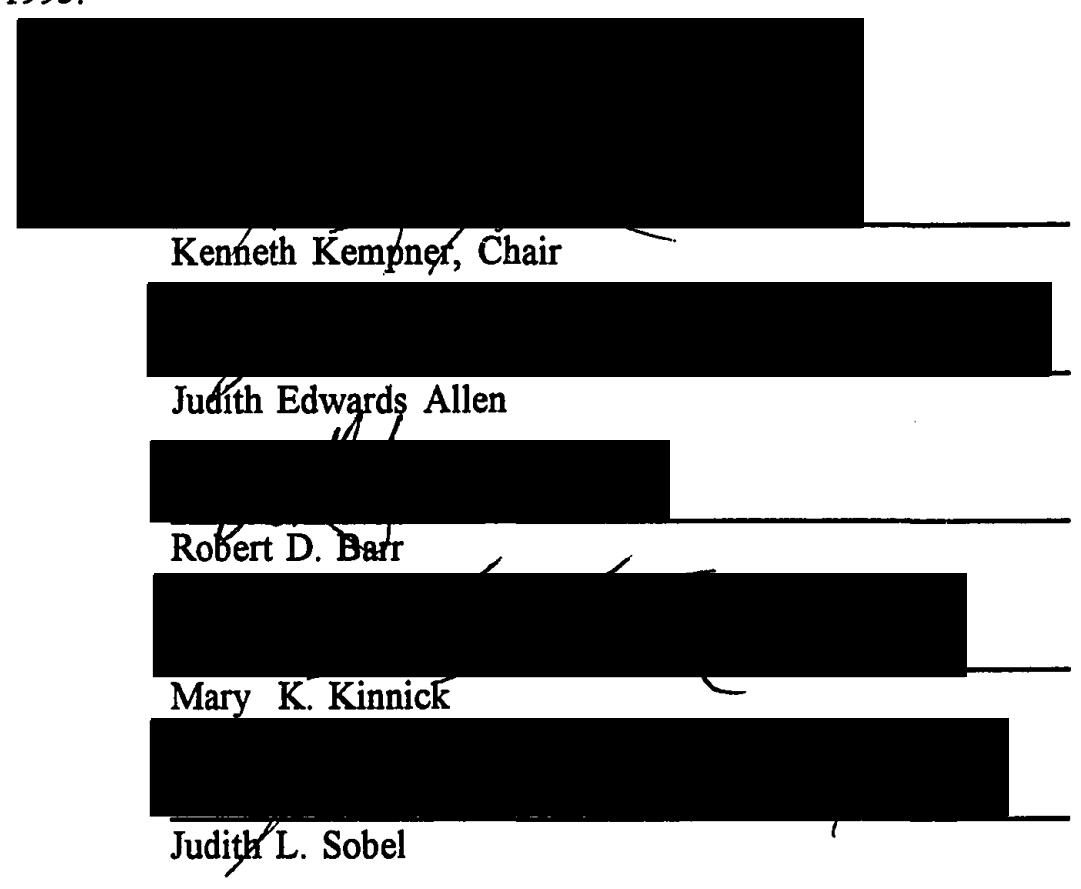

APPROVED:

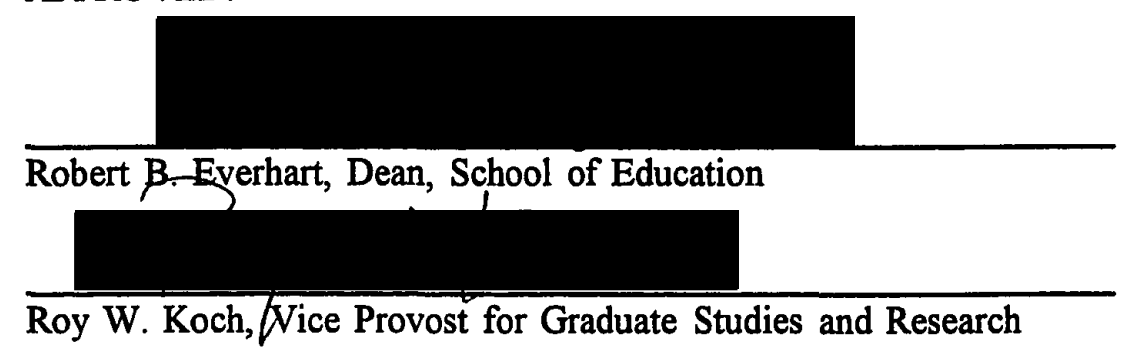


AN ABSTRACT OF THE DISSERTATION OF Dian Dee Connett for the Doctor of Education in Community College Education presented July 1, 1993.

Title: The Culture of an Alternative Education Program:

A Participant Observational Study

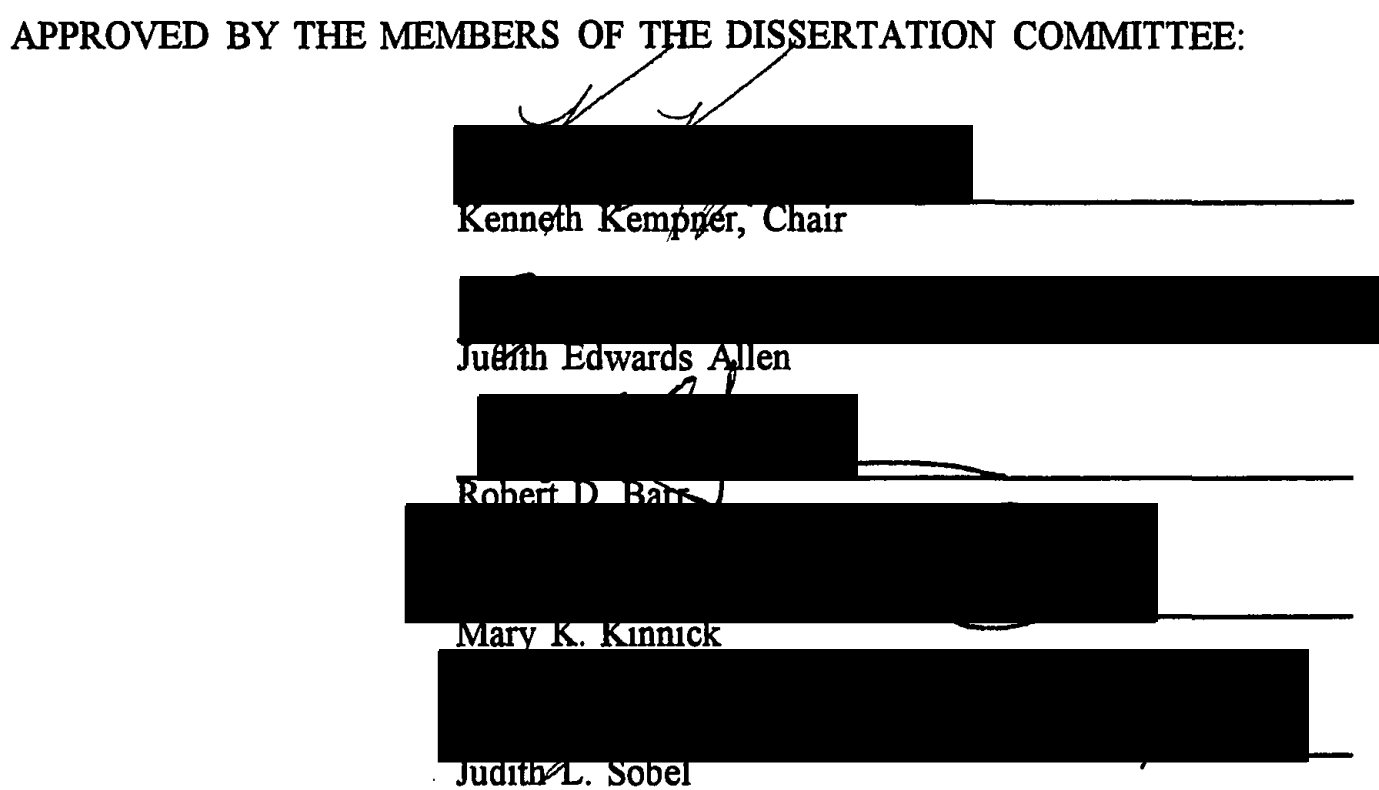

This study is participant observational research focused on the culture of one successful alternative education program. The survey of the literature showed that the problem of high school dropouts is one of large numbers and persistence over time. Most research in the past attempted to list characteristics of high school dropouts or elements of successful alternative education programs. Researchers such as Wehlage (1986) and Catterall (1987) have begun to look at a different approach. Their work 
looks at schools as systems and suggests that educators should direct their attention to the interaction of the school environment with the characteristics of the students. This view fits into a body of work that looks at schools and classrooms as microcultures.

The work presented here looks at an alternative education program as a microculture and asks "What appears to be the distinguishing microculture created by the participants of Tri City Alternative Program?" The researcher collected data from interviews, observations, student projects and work, staff meetings, and program materials and records. The data were analyzed and organized to find patterns of behavior and interactions and to determine the meaning the participants attached to their interactions.

The elements that distinguish the microculture of the alternative education program were divided into the features of the context and the features of the interactions. The elements of the context were described by the physical setting, the daily instructional schedule, and the non-instructional daily schedule. The elements of the interaction were described by clearly stated expectations, staff and student attention to culture, sense of caring and defining competence, and sense of humor.

The researcher concludes by proposing three future areas of work. One is to develop a model of synchronization between the context and interactions of educational programs. The second is to complete additional cultural studies of high school dropouts. The last recommendation is to train teachers and students to use participant observational techniques in their classrooms to build their understanding of their own microcultures. 
TABLE OF CONTENTS

PAGE

LIST OF TABLES $\ldots \ldots \ldots \ldots \ldots \ldots \ldots \ldots \ldots \ldots \ldots \ldots \ldots \ldots$

LIST OF FIGURES $\ldots \ldots \ldots \ldots \ldots \ldots \ldots \ldots \ldots \ldots \ldots \ldots \ldots$ vii

\section{CHAPTER}

I INTRODUCTION $\ldots \ldots \ldots \ldots \ldots \ldots \ldots \ldots \ldots \ldots \ldots \ldots$

Participant Observational Research $\ldots \ldots \ldots \ldots \ldots \ldots$

Cultural Perspective $\ldots \ldots \ldots \ldots \ldots \ldots \ldots \ldots$

Presentation of the Study $\ldots \ldots \ldots \ldots \ldots \ldots$

II REVIEW OF THE LITERATURE $\ldots \ldots \ldots \ldots \ldots$

Dropout Focused Research $\ldots \ldots \ldots \ldots \ldots \ldots$

Investigation Into Microcultures of Schools

And Classrooms . . . . . . . . . . . . . . . 22

Summary of the Literature $\ldots \ldots \ldots$. . . . . . . . . . 29

III $\quad$ RESEARCH QUESTIONS $\ldots \ldots \ldots \ldots \ldots \ldots \ldots \ldots \ldots \ldots$

Introduction of Participant Observational Research $\ldots \ldots .31$

Research Questions $\ldots \ldots \ldots \ldots \ldots \ldots \ldots$

Data Collection and Analysis $\ldots \ldots \ldots \ldots \ldots$ 
IV DATA AND FINDINGS I: PROGRAM STRUCTURE

AND CONTEXT $\ldots \ldots \ldots \ldots \ldots \ldots \ldots$

The Structure of the Physical Setting $\ldots \ldots \ldots \ldots \ldots$

The Daily Instructional Setting $\ldots \ldots \ldots \ldots \ldots \ldots$

Outside the Daily Instructional Schedule $\ldots \ldots \ldots \ldots \ldots$

Interviewing Students

Staffings and Staff Meetings

Counseling and Advising Students

$\because \quad$ DATA AND FINDINGS II: PARTICIPANT INTERACTIONS $\ldots \quad$. 59

Clearly Stated Expectations $\ldots \ldots \ldots \ldots \ldots \ldots$

Staff and Student Attention to Culture .......... 62

Sense of Caring and Defining Competence $\ldots \ldots \ldots \ldots 6$

A Sense of Humor . . . . . . . . . . . . . . . . 69

VI CONCLUSIONS AND FUTURE DIRECTIONS . . . . . . . 73

The Synchronization of Cultural Context and Interactions $\ldots \ldots \ldots \ldots \ldots \ldots \ldots$

Additional Cultural Studies of Dropouts $\ldots \ldots \ldots \ldots \ldots 77$

Benefit of Participant Observational Research . . . . . . . 79

REFERENCES $\ldots \ldots \ldots \ldots \ldots \ldots \ldots \ldots \ldots \ldots \ldots \ldots \ldots \ldots$

\section{APPENDICES}

A DAIIY GOAL SHEET SAMPLE . . . . . . . . . . . 89

B WEEKLY GOAL SHEET SAMPLE ............ 91 
C SENTENCE COMPLETION SAMPLE .............. 93

D INTERVIEW FORM SAMPLE . . . . . . . . . . . . . 95

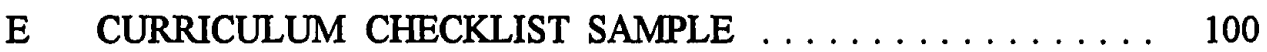




\section{LIST OF TABLES}

$\begin{array}{lll}\text { TABLE } & \text { PAGE }\end{array}$

I Attrition Rate in Selected States

and Total Dropout Numbers $\ldots \ldots \ldots \ldots \ldots 11$

II Dropout Rates and 1990 Completion Status $\ldots \ldots \ldots \ldots \ldots 12$

III Unemployment Rates and Annual Earnings

for Dropouts and Graduates 1982 . . . . . . . . . 19 


\section{LIST OF FIGURES}

1. Simplified Catterall Model of Dropping Out . . . . . . . . . . . 15

2. TriCity Alternative Floor Plan $\ldots \ldots \ldots \ldots \ldots \ldots$

3. Student Attendance and Graduation Boards ............. 43

4. Samples of Display Boards . . . . . . . . . . . . . 44

5. Sample of Student Work Directions $\ldots \ldots \ldots \ldots \ldots \ldots$

6. Synchoronization Model $\ldots \ldots \ldots \ldots \ldots \ldots \ldots \ldots$ 


\section{CHAPTER I}

\section{INTRODUCTION}

Every year in the United States there are high school students who do not complete school. They are called dropouts or non-completers and number in the hundreds of thousands. Nationally, about 347,000 youth dropped out of school in the year ending October, 1990. They added to the pool of 3.4 million people in the age range of 18 to 24 years who have never completed high school (U.S.

Department of Commerce, 1992). In Oregon, 8,624 youth dropped out of high school in 1991 compared to 8,603 in 1990 , even though the rate decreased from $25.4 \%$ to $24.1 \%$ (Oregon Department of Education, 1992, p.1).

Dropouts and potential dropouts are the targets of educational reform efforts, new services, and increased research attention. Rumberger writes that more interest and "more research has appeared on the problem of dropouts in the last 2 years than in perhaps the previous 15" (Rumberger, 1987, p.101). There is also growing political attention. Both state and federal officials have adopted ambitious goals about reducing dropout rates and maintaining students in school until they complete

a diploma. The "Oregon Benchmarks" articulates the state goal of reducing the high school dropout rate to $7 \%$ by the Year 2000 , while reporting the 1990 rate at $27 \%$ (Oregon Progress Board, 1991, p.30). Goal Number Two in "The National 
Education Goals Report" is "By the Year 2000, the high school graduation rate will increase to at least 90 percent" (National Education Goals Panel, 1991, p.6).

One major area of educational research interest is investigating possible "solutions" (Rumberger, 1987, p.103) to the problem of dropouts. Alternative education programs are considered solutions to the dropout issues because they seek to educate youth who have left or who are at risk of leaving the traditional educational system. The approach of offering alternatives has even been incorporated into Oregon's 21st Century Schools legislation (S.B.3565). Recommendations about alternative learning environments for potential and current high school dropouts were presented to the Oregon State Board of Education in October, 1992 (Oregon Department of Education, 1992, p.7).

The study presented here seeks to add to the understanding of how an alternative education program serves high school dropouts. It will describe the culture of a program and paint a picture of an educational setting with "meaningperspectives in which it makes sense to learn" (Erickson, 1986, p.127) for young people who have previously experienced failure. The setting is an alternative education program, Tri City Alternative Program (TCAP), listed as a model response to the Oregon agenda of serving non-completers (Oregon Office of Community College Services, 1992). It has been named a model program to serve high risk youth (Oregon Youth Coordinating Council, 1985). It is listed as an approved alternative education program and is operated by a community college, as are $20 \%$ of the programs registered with the Oregon Department of Education (1991). In an 
external evaluation report, the program was reported as exceeding national standards for high risk youth programs with a student completion rate of $85 \%$ (Portland State University, 1986.)

\section{PARTICIPANT OBSERVATIONAL RESEARCH}

The study presented here is the result of participant observational research conducted over the course of two years. The study utilizes the background of the researcher and other staff participants that accounts for eight years of program history. The focus of the study is on the culture, as evidenced by the day-to-day interactions and operations of the alternative education program, and, more importantly, the interpretations of those interactions made by the program staff and students.

This study illustrates four major characteristics of qualitative research: assumptions regarding the world, research purpose, research approach, and role of the researcher (Firestone, 1987). Qualitative research is rooted in the belief that reality is a socially constructed phenomenon and that the researcher sorts out multiple realities by understanding the emic perspective (Fetterman, 1984, p.23). Great effort has been made to present the students' and staff's interpretation of the program in which they are involved. These are the "natives" who create the culture that allows former high school dropouts to succeed or fail.

Qualitative research is "a descriptive and interpretative activity whose purposes are to understand rather than to judge and to examine acts of human behavior as part 
of larger cultural systems" (Wolcott, 1984, p.179). This study adds to the understanding of the general problem of high school dropouts by describing one successful alternative program. Rumberger (1987), in a review of the literature, describes most research in the area of high school dropouts as correlational, identifying factors related to dropping out but lacking in good description about dropouts and about features of programs working with dropouts.

The approach of the qualitative researcher is exploratory. She uses literature and previous research to develop "insightful questions" and attempts to "avoid prior commitment to any theoretical model" (Yin, 1984, pp.20-25). This alternative school study started with general questions that were refined and changed as I was able to check and recheck the participants' understanding of the existing culture.

The researcher's role is one of immersion in qualitative research. The person is the primary research tool, gathering data through all the senses and tailoring instruments to the situations (Spindler, 1982). The role of the participant observer in this study is an example of researcher immersion. I utilized knowledge of the program history and present events to explore the implicit aspects and meanings of the alternative program culture. Observations, surveys, records, interviews, and student projects were all used to add to the portraiture, as Lightfoot (1983) did when describing high school programs.

This approach is particularly appropriate to the problem. As the review of the research will show, there is a surprising lack of work done at the descriptive, interpretative level. Work in the field has been slowed by educators who are just 
beginning to standardize counting procedures for high school dropouts. Much of the work on alternative education programs for dropouts has focused on lists of program characteristics. There is only recently work by Catterall (1987) and Wehlage (1986) that looks at dropouts as part of the larger culture or system of education.

\section{CULTURAL PERSPECTIVE}

Green and Leigh $(1989$, p.6) define culture as "a definable entity with a particular history" and having sets of values, behaviors, and beliefs that affect how individuals interpret the world and act on it. In order to study a culture, researchers look for "cohesive elements and patterns of behaviors" (Kempner, 1990, p.221). It is culture that provides "the distinct structure or pattern" (Sarason, 1971, p.12) for individuals to act and to interact with each other.

Small, distinct groups such as families and classroom units are called subcultures by some researchers and microcultures by others. Green and Leigh (1989) maintain that cultures, sub-cultures, and microcultures are, from a practical definition, alike. They represent a system of believing, acting, deciding, and interpreting. Whether one says the study is of a culture or sub-culture, the task is the same, to discern the patterns of participants' actions and interactions. Erickson uses the term microculture as "the typical unit of analysis studied by fieldwork researchers" (1986, p.128) to focus on local meanings and understandings that participants share as they interact on a regular basis. 
I will refer to the study as having a cultural perspective. That is, the focus is on patterns of behaviors that show an outsider what the participants believe, value, and know. I will refer to the specific elements of Tri City Alternative Program as its microculture. The major research question is "What appears to be the distinguishing microculture created by the participants of Tri City Alternative Program?"

A cultural perspective seems particularly valuable in looking at dropout related issues. Previous studies have shown the incidence of dropping out to be significant and persistent over time. It can no longer be assumed that the problem lies solely with the individual youth. Researchers, such as Catterall (1987) maintain that attention must be given to the interaction between schools' academic and social cultures and the students. The early work of Spring (1976) pointed out the strong influence schools have on students' access to future roles and careers. Researchers such as Wolcott (1982), Lightfoot (1983), and Erickson (1982) have produced descriptive studies that reveal the complexities of schools. The works of Catterall (1987) and Wehlage (1986) look specifically at dropouts within these complex systems. All of these approaches have added to a growing body of work that looks at schools as systems or cultures and have pointed to the need for new studies focusing on the complex nature of schools and dropouts. 


\section{PRESENTATION OF THE STUDY}

Literature and previous research relevant to the study of a successful alternative program will be presented in Chapter II. This will include outlining the scope of the dropout problem as well as reviewing the types of research that have appeared.

Chapter III will discuss the research questions. I will also show how a researcher doing qualitative research must be open to refining questions as field work continues.

An overview of the setting, students, and staff along with the data from the two year period of participant observation will be presented in Chapter IV and V. Data were gathered to describe the daily life of the participants as revealed in the program structure and participant interactions. It was analyzed to help reveal the meanings attached to the events.

Conclusions and future directions will be presented in Chapter VI. There is the need to look both at the future of this type of research and the topic of high school dropouts. 


\section{CHAPTER II}

\section{REVIEW OF THE LITERATURE}

This study seeks to understand the program operations and participants' interactions that create a microculture in which high school dropouts choose to continue their education. Two major areas of previous research have guided the effort: research in the field of high school dropouts and investigations into the microcultures of schoois and classrooms.

\section{DROPOUT FOCUSED RESEARCH}

In his review of dropout research, Rumberger (1987) divides the existing literature into 4 categories: "incidence causes, consequences, and solutions" (p.103, emphasis added). These four categories provide a framework for review of the

research. Research related to the incidence of the problem of high school dropouts is concerned with the methods of counting dropouts, including defining the term and attempting to track the individuals. State departments of education, the U.S. Census Bureau, the U.S. Department of Education, the U.S. Department of Labor, researchers, and individual school districts are all interested in determining the number of high school dropouts. They are all faced with deciding which cohort to use a base, how to determine membership in the base, when to label a student a 
dropout, how long to track the cohort, and whether subsequent education, such as GED attainment, affects dropout status.

There are efforts under way to standardize dropout definitions and counting procedures. The U.S. Department of Education and the Council of Chief State School Officers are attempting to produce consistent policies for the production of dropout statistics. For many researchers, this lack of consistent base data points out that the area of high school dropouts has been relatively neglected. As Dale Mann (1987) said, "What we care about, we learn to count". While this may reflect the lack of consistency at the national level, there are significant strides being made in states like Oregon where the Department of Education (1987) began a study in 1987 to study high school dropouts. The result has been the Oregon Early School Leavers study that focuses on "How many Oregon students leave school early? What later educational or training experiences do these leavers have? What are their job histories?"

Even with its shortcomings, the research on dropout incidence points out three major factors. First, the majority of dropouts do not complete their education after leaving high school. The California State Department of Education reports that its attrition could be reduced from $30 \%$ to $20 \%$ if it adjusted for the students expected to complete an equivalent high school education by the age of 30 years. Other researchers report that perhaps as many as $40 \%$ of high school dropouts might receive an equivalent diploma (Kirsch, 1986). It is apparent that the majority of dropouts are not choosing to complete their education. 
Second, the incidence data shows the dropout rate to be increasing slightly but to be relatively stable over time (see Table I). "The percentage graduating (nationally) peaked in 1965 at just over 76 percent and has been very stable at about 75 percent for the last 20 years" (Catterall, 1987, p.25). Some researchers such as Mann and Apple would maintain this shows the systemic nature of the problem, the sorting process that schools use. Mann (1986) cynically suggests that dropouts are good for schools. They insure the success of reform movements by increasing the odds of success for educators.

Third, all of the incidence studies conclude that dropout rates vary for different social and ethnic groups (see Table II). Dropout rates are higher for racial and language minorities. In addition, researchers have found dropout rates vary greatly from school to school even when racial composition is taken into account (Toles, 1986). The problem of dropping out of high school tends to affect certain types of youth more often than others.

The literature related to the causes of dropping out of high school is concerned with identifying the characteristics of dropouts and suggesting the underlying reasons for dropping out. Much of the research has focused on surveys of dropouts, asking them why they choose to leave high school. Rumberger (1987) found almost half of all dropouts identify school related issues as the primary reasons for leaving. These included poor performance, dislike of school, and expulsion. Catterall (1987) maintains that the 1983 High School and Beyond Survey by Peng and the 1983 
TABLE I

ATTRITION RATE IN SELECTED STATES AND TOTAL DROPOUT NUMBERS

\begin{tabular}{|c|c|c|c|}
\hline State & 1972 & 1982 & 1984 \\
\hline Alabama & 34.6 & 32.9 & 37.9 \\
\hline California & 20.1 & 31.1 & 36.8 \\
\hline Connecticut & 16.6 & 28.8 & 20.9 \\
\hline Florida & 27.9 & 34.6 & 37.8 \\
\hline Georgia & 35.2 & - & 36.9 \\
\hline nlinois & 22.0 & 25.2 & 25.5 \\
\hline Kansas & 17.2 & 19.1 & 18.3 \\
\hline Louisiana & 33.5 & 36.0 & 43.3 \\
\hline Michigan & 19.0 & 27.3 & 27.8 \\
\hline Nevada & 25.0 & 24.7 & 33.5 \\
\hline New Jersey & 20.3 & 21.9 & 22.3 \\
\hline New Mexico & 23.1 & 28.4 & 29.0 \\
\hline New York & 25.3 & 33.7 & 37.8 \\
\hline Ohio & 19.7 & 22.5 & 20.0 \\
\hline Oregon & 20.8 & 28.3 & 26.1 \\
\hline South Carolina & 30.8 & 35.7 & 35.5 \\
\hline Texas & 29.8 & 31.8 & 35.4 \\
\hline Washington & 16.1 & 23.1 & 24.9 \\
\hline Wyoming & 16.9 & 21.7 & 24.0 \\
\hline \multicolumn{4}{|c|}{ (Adapted from Rumberger, 1987.) } \\
\hline Year & Number of Dropouts & & \\
\hline 1990 & 347,000 & & \\
\hline 1989 & 404,000 & & \\
\hline 1988 & 461,000 & & \\
\hline 1987 & 403,000 & & \\
\hline 1986 & 421,000 & & \\
\hline 1985 & 504,000 & & \\
\hline
\end{tabular}

(Adapted from the U. S. Department of Commerce, Bureau of the Census, 1992.) 
TABLE II

DROPOUT RATES AND 1990 COMPLETION STATUS

\begin{tabular}{|c|c|c|c|c|c|}
\hline Cohort & 1968 & 1978 & 1980 & 1982 & 1984 \\
\hline $16-17$ year olds & 7.8 & 8.8 & 8.8 & 7.3 & 6.8 \\
\hline white males & 6.9 & 9.6 & 9.3 & 7.3 & 7.3 \\
\hline white females & 7.6 & 8.7 & 9.2 & 8.0 & 6.9 \\
\hline black males & 10.1 & 5.2 & 7.2 & 6.4 & 5.5 \\
\hline black females & 14.2 & 9.4 & 6.6 & 5.5 & 4.9 \\
\hline Hispanic males & - & 15.6 & 18.1 & 12.2 & 13.6 \\
\hline Hispanic females & - & 12.2 & 15.0 & 15.9 & 12.7 \\
\hline $18-19$ year olds & 15.7 & 16.7 & 15.7 & 16.7 & 15.2 \\
\hline white males & 14.3 & 16.3 & 16.1 & 16.6 & 15.8 \\
\hline white females & 14.6 & 15.0 & 13.8 & 14.9 & 14.0 \\
\hline black males & 23.8 & 25.8 & 22.7 & 26.4 & 19.7 \\
\hline black females & 24.7 & 22.8 & 19.8 & 18.1 & 14.5 \\
\hline Hispanic males & - & 36.6 & 43.1 & 34.9 & 26.2 \\
\hline Hispanic females & - & 39.6 & 34.6 & 31.3 & 26.0 \\
\hline \multicolumn{6}{|c|}{ (Adapted from Rumberger, 1987.) } \\
\hline Race & \multicolumn{5}{|c|}{1990 Completion Status } \\
\hline White (19-20 yrs.) & \multicolumn{5}{|c|}{$87 \%$} \\
\hline Hispanic (19-20 yrs.) & \multicolumn{5}{|c|}{$60 \%$} \\
\hline Black (19-20 yrs.) & \multicolumn{5}{|c|}{$78 \%$} \\
\hline
\end{tabular}

(Adapted from National Education Goals Panel, 1991.) 
Survey of Youth Labor Market Experience are the best inquiries into self reported reasons for dropping out. "Dislike of school and having poor grades head the list of volunteered reasons and stand apart as the most frequent responses. About a third cite such reasons" (Catterall, 1987, p.29).

The results of these surveys can best be viewed as identifying factors related to dropping out, rather than uncovering actual causes. Catterall (1987) points out that most studies do not include data about student characteristics or other related variables because dropouts are difficult to find, track, and follow. This limits the causal information to antecedent information available before the youth made the decision to drop out. In 1987 Rumberger stated, "No one really knows what causes students to drop out of high school" (1987, p.109). In the ensuing years, researchers such as Frymier (1992) have identified factors associated with dropping out of school. Thirty three items have been linked to dropping out, and students who drop out tend to have clusters of multiple factors such as having low reading scores, having been abused, and having excessive absences (Frymier, 1992).

Another component to understanding dropping out of high school is to look at how the individual's characteristics interact with school environments. One promising approach by Catterall (1987) does integrate current causal research into a process model of disengagement from school. He bases his model on research on attrition from college and on Durkheim's theory of an individual's rejection of society leading to suicide. The "focus (is) on the central construct of institutional integration and its influence on the individual's continued enrollment" (Catterall, 
1987, p.39). Catterall uses the research and Durkheim's work to show there are two sub-systems in schools that are critical to a student's intergration into the educational system. Those are the academic sub-system and the social sub-system. "Research suggests that the absence of individual integration with either or both of these subsystems can lead to withdrawal or expulsion" (Catterall, 1987, pp.39-40).

Figure 1 shows the visual representation Catterall uses to explain his disengagement model. The academic sub-system of the school requires goal commitment: attainment of grades, future orientation, acceptance of the values of school. Successful integration into the social sub-system of the school depends on successful interactions with peers, teachers, administrators, and others involved in the life of the school. There is interaction between both of these sub-systems. One student may value the social interactions of school so much that he/she is willing to suffer failure in the academic sub-system in order to continue friendships. In most cases, however, lack of integration into the academic sub-system usually leads to failure, and unsuccessful integration into the social sub-system leads to expulsion. Lack of success in either sub-system increases the likelihood the student will drop out of school.

Catterall also includes factors outside the school that may influence student continuation. The family and the student's innate ability can influence either academic or social performance. Early successes or failures in these areas may contribute to strong or weak alliances with academic goals or with social interaction. 


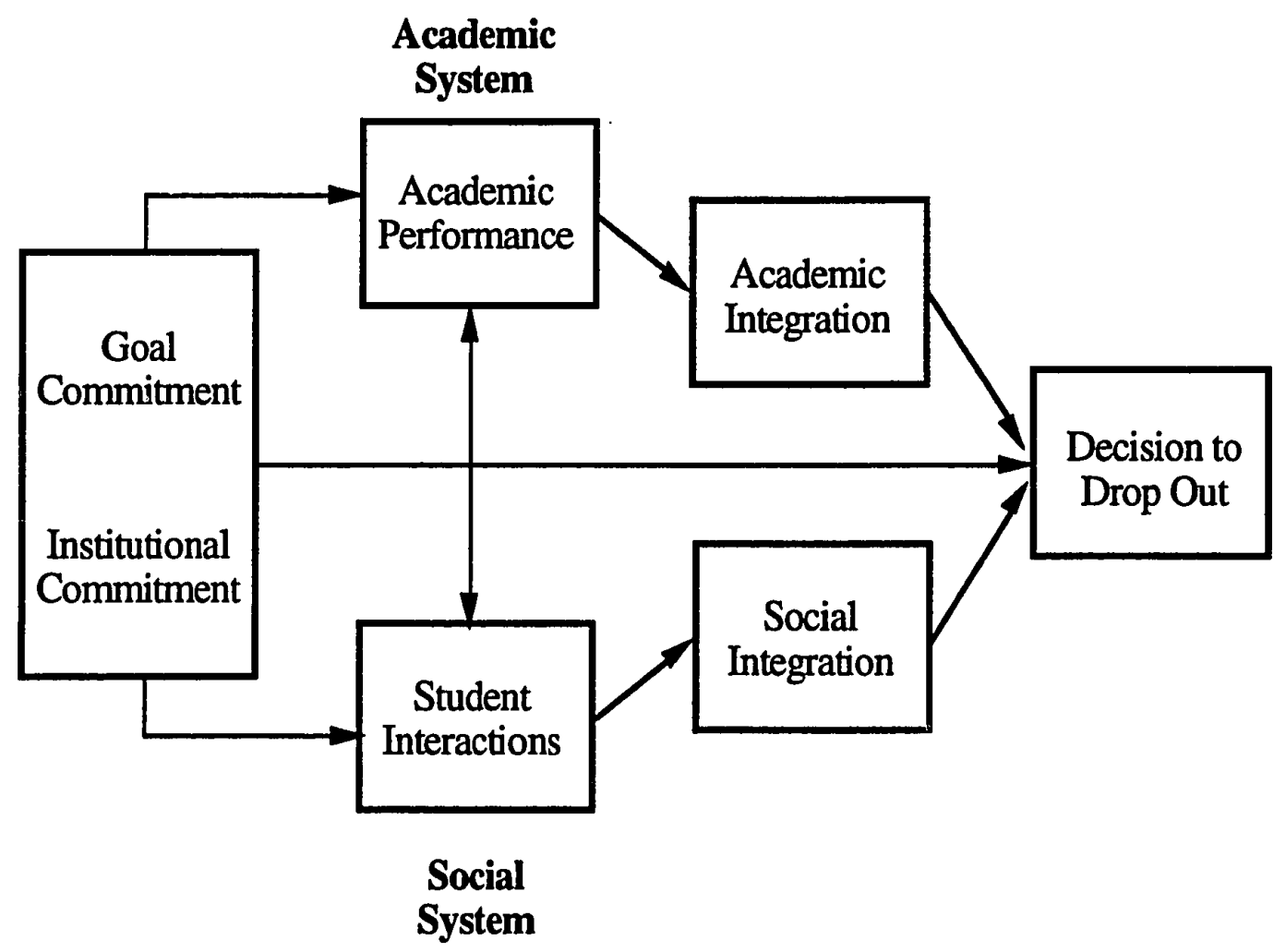

Figure 1. Simplified Catterall model of dropping out. (Adapted from Catterall, 1987.) 
In addition, outside forces such as the economy, early pregnancy, and community involvement exert influence over decisions to drop out.

Perhaps the most powerful aspect of Catterall's model is "its depiction of cummulative integration deficiencies" (Catterall, 1987, p.45) and its attention to the institutional sub-systems that enhance or detract from integration.

There are good reasons for believing that the burden of successful integration into school should not fall exclusively on the youngster. For example, the regular rejection of school by a fourth of American students and its bare tolerance by an additional undetermined fraction are indicative of an institutional rather than individual pathology. It appears schools have developed norms, practices, and policies that aggravate the life conditions faced by many youngsters (Catterall, 1987, p.46).

Recent work by Wehlage and Rutter (1986) supports the notion that students progressively reject school as a result of the interaction of school and individual characteristics. Wehlage and Rutter have extensively analyzed the High School and Beyond data searching for insights into why students drop out of high school. They caution that it is not possible from current research to determine if characteristics like external locus of control, low self esteem, and negative school attitude exist before a child comes to school or develop as a result of school experiences. The data from High School and Beyond show that few of the eventual dropouts expected to leave school early and many anticipated completion. Wehlage and Rutter write "it appears that rather than broadly promoting the realization of youthful expectations schools now work to undermine them, except for those students who are most obviously facile with a restricted conception of learning" (1986, pp.381- 
382). Researchers should look for the elements of the structure of schools that cause these adolescents to decide that school is not for them.

Wehlage and Rutter assert that there is a mis-match between the way schools are structured for discipline, learning, and interaction and the environment many students need to be successful. Schools are perceived as unpleasant places where negative things happen to youth. "The process of becoming a dropout is complex because the act of rejecting an institution as fundamental to the society as school must also be accompanied by the belief that the institution has rejected the person" (Wehlage and Rutter, 1986, p.385).

The proposition that the interaction between school conditions and student needs is responsible for decisions to drop out is supported by the finding that there is a marked increase in self esteem measures after a student drops out of high school. Wehlage and Rutter (1986) found that high school dropouts had an overall gain in self esteem scores comparable to a group of college bound students. They suggest "that schools in performing their sorting function for society may be unnecessarily harsh and discouraging to many adolescents" (Wehlage and Rutter, 1986, p.389). Leaving school, then, gives these youth a chance to experience more successful opportunities in the adult world.

Research into the consequences of leaving high school before graduation looks at the social and individual detriments. There are a few educators who suggest satirically that dropping out can have a beneficial result. Mann points out that "dropouts are a growth industry" (1986, p.313); they help justify community college 
budgets, they help insure that teachers are more successful with the remaining students, and they represent a problem that has been with us since the beginning of schooling. Even the research by Wehlage and Rutter (1986) that suggests dropping out of school may play a role in improved self-esteem for some youth, especially when the alternative is to stay in school and be unsuccessful or disruptive, is not viewed as an argument for allowing students to drop out of school.

Dropping out of school is viewed as having serious consequences for the youth and for society. The two areas most often cited as affected by dropping out are economic/employment and personal well being. Because of lower academic skills and lack of academic credentials, high school dropouts suffer higher unemployment rates and receive lower salaries than graduates (Table III). This translates into lifetime earnings for dropouts that are $\$ 250,000$ less than graduates (U.S. Department of Commerce, 1992).

The effect of dropping out on personal well being is more difficult to track but no less alarming. Increased unemployment and low wages have been linked with greater rates of admissions to state hospitals, suicides, and poor physical health.

The social cost of dropping out is often measured in lost resources or added social spending requirements. Levin (1986) organized the social consequences into seven categories:

1) Unrealized national income

2) Less tax revenue

3) Increased need for social services 
TABLE III

UNEMPLOYMENT RATES AND ANNUAL EARNINGS

FOR DROPOUTS AND GRADUATES 1982

\begin{tabular}{lcc} 
Cohort & Employment & Earnings \\
\hline Males & & \\
Dropouts & 43.4 & 10,964 \\
Graduates & 21.2 & 13,088 \\
& & \\
Females & & \\
Dropouts & 38.3 & 8,414 \\
Graduates & 23.9 & 10,235
\end{tabular}


4) Increased crime and imprisonment rates

5) Less participation in political/social systems

6) Reduced mobility

7) Poorer levels of health

Mann (1986) agrees that it is important to note such statistics as $\$ 71$ billion dollars of potential taxes lost to government and $\$ 25,000$ per year to house one prison inmate who is often a high school dropout. He graphically makes the point pertinent to individuals by relating:

when my grandfather retired in 1950, his Social Security Trust Fund income was guaranteed by seventeen currently employed workers who were paying into the fund. If I could retire in 1992, my Social Security checks would be supported by only three workers and one of those would be minority. With most of some youth groups both out of school and unemployed, how much wasted human capital can I afford? (Mann, 1986, p.315)

The literature addressing the solutions to the dropout problem is often contradictory and at best superficial. Each researcher, writer, and consultant seems to have his/her key components for successful alternative programs. Conrath (1986) advises educators to follow 10 principles for successful programs:

1) Be willing to spend money

2) Target your students

3) Clarify your purpose

4) Assign top quality staff members to the program

5) Give your staff autonomy

6) Set aside planning time

7) Structure your program for success 
8) Coordinate teacher efforts

9) Use teaching strategies that work

10) Don't ignore school politics

Even at first glance, these principles leave a number of questions in the practitioner's mind: In clarifying your purpose, what do you do if that purpose is different from the youths' goals? What teaching strategies work, in which situations, in which combinations, with which students?

On deeper examination, there are more serious problems with these seemingly common sense principles. Conrath advises targeting the program to serve specific students as one principle. Yet, in the examples related to clarifying the principle "Structure your program for success", he describes an alternative high school that did not differentiate high risk students from academically successful students. He praises this approach because it does not label students. Which principle should be followed?

To add to the confusion, other authors have totally different principles they claim have been proven successful. Mann (1986, pp.318-319) calls his components the "four Cs": cash, care, computers, and coalitions. The cash is related to work experience opportunities for students. The care comes from teachers providing a great deal of personal contact. The computers are used to provide computer assisted instruction and student management functions. The coalitions describe a multiagency approach to providing jobs, education, counseling, recreation, etc. to address the many needs of high risk youth. 
The GAO report to Congress, School Dropouts: Survey of Local Programs

(U.S. General Accounting Office, 1987, p.20), lists 8 factors contributing to dropout program effectiveness:

caring and committed staff

nonthreatening environment for learning

low student-teacher ratio

individualized instruction

program flexibility

links with social service agencies

involvement of parents in students' development

links with employers

The report goes on to say that the first two factors, the staff and the environment, were rated higher than any of the other factors, sometimes as much as 4 to 1 .

Green and Baker (1986) acknowledge the great diversity in the reporting of program characteristics. They relate it to the lack of systemic research and program evaluation. The reports of program effectiveness have relied on program descriptions and practitioners' opinions.

\section{INVESTIGATION INTO MICROCULTURES OF SCHOOLS AND CLASSROOMS}

The work of researchers like Erickson, Lightfoot, and others illustrates a way of investigating schools and classrooms as microcultures. These studies "seek to understand ways in which teachers and students, in their actions together, constitute 
environments for one another" (Erickson, 1986, p.128). Groups of people, like students and teachers, who regularly interact form social organizations and construct meaning from their interactions. Erickson (1986) labels these groups microcultures and stresses the importance of understanding the meanings each microculture places on its interactions. The meanings may be only slightly different from classroom to classroom, from microculture to microculture, but these are the "subtly different meaning-perspectives in which it makes sense to students to learn in one classroom and does not make sense to learn to another classroom, from a student's point of view" (Erickson, 1986, p.127).

Some of the first efforts to look at classrooms as microcultures involved trying to understand why ethnic groups, such as American Indians, tended to experience high rates of failure in public schools. Erickson and Mohatt (1982) studied Canadian classrooms of Odawa Indian children taught by Indian and non-Indian teachers. The researchers identified three areas of classroom behavior that are culturally influenced and that have an effect on Indian children's participation. The behaviors involved the classroom tempo, the directiveness of the teacher, and the different ways to stimulate speaking. The researchers found vivid examples of how Indian and non-Indian teachers differed in their patterns of interaction with respect to those three areas of behavior.

Erickson and Mohatt (1982) went on to suggest that the classrooms with Indian and non-Indian teachers created very different microcultures because of the difference in interaction patterns. Further, because the non-Indian teachers created 
microcultures that conflicted with the interaction patterns the children encountered at home and on the reservation, the children had difficulty participating in the classroom activities in the manner expected by the teacher.

The researchers used the results of their study to train non-Indian Canadian teachers in classroom interaction patterns that resembled Indian patterns. The teachers were able to utilize the new styles and develop classroom microcultures more closely reflecting Indian interaction. Mohatt and Erickson concluded it was possible to solve "classroom issues through an analysis of inter-actional events" (Erickson and Mohatt, 1982, p.139) while paying attention to the classroom microculture and consciously affecting it.

There have been several investigations of community college cultures. London (1978) produced an ethnographic portrait of a community college serving mostly working class students who valued education and endorsed its role in future success, yet, still engaged in behaviors (skipping classes, antagonizing teachers) that resulted in failure. London uncovered evidence of a student culture that was in conflict with a faculty culture. Faculty expected intellectualizing, and students responded by belittling that type of activity. The student culture that supported activities contrary to the faculty's played an important role of protecting individual students against possible failure to succeed within the college institution. In essence, the student culture redefined success as not including academic achievement.

In an examination of a community college serving primarily urban black students, Weis (1985) again found strong evidence of a student culture helping to 
perpetuate students' academic failure. The researcher points to ways faculty and student culture interact to create hidden curriculum. One example is the use of time. Students, faculty, and administration take a variety of actions trying to seize control of how students use time, i.e. reporting late to class, skipping class, not studying. "The form and content of the curriculum is in large part the result of ongoing interaction between faculty and students at the level of their own lived culture" (Weis, 1985, p.89). Other elements such as use of standard English and staff involvemnt are important in the hidden curriculum.

Weis concludes her study by illustrating that the successful students at the college she studied had to stay out of the pre-dominate student group and culture. "Success there involves a break from the collectivity, and a willingness to adopt a new cultural style" (Weis, 1985, p.120). This is particulary difficult because the students at this college had histories of past academic difficulties. They had enrolled in this school as a last chance. "Students at Urban College are the failures of the public school system in the United States - the students who could not or would not work within teacher categories" (Weis, 1985, p.125).

Kempner's (1990) case study of a Northwest community college identified four themes that described the college culture. Among them were elements that facilitated and hindered learning. Students, faculty, and administrators all participated in these actions to create the institution's culture on a daily basis.

In a more general look at learning, Erickson (1984) stresses the importance of the social relationships in building the framework for learning. He calls this 
framework scaffolding that is "the fluid, interactional system of social and cognitive support" (Erickson, 1984, p.533) for learning. This interaction (scaffolding) is obvious when observing successful learning situations between mothers and children. There is a great deal of give and take exchange in which both the parent and child shape the learning and build scaffolds that reach out as a bridge to help the child move from one level of understanding to another. Erickson argues that most classrooms limit the scaffolding to teacher directed activities that are very one sided. This sets up an environment in which the learners cannot participate in the problem solving and cannot help to build the scaffolding they need to learn.

This factor is not a fault of individual children or teachers. It is an aspect of social organization in schools--constraints on learner choice in task definition and on the ability of teachers and students to construct cognitive scaffolding together as they work on learning tasks. Some constraints come from outside the classroom: from administrative regulations and standard operating procedures and from the designers of curriculum materials. Other constraints come from within the room: from teachers'(and children's) culturally learned assumptions about the proper conduct of school teaching and learning (Erickson, 1984, pp.534-535).

Erickson (1984) supports an organizing theory to the research conducted on classroom microcultures. That is resistance theory. The resistance theory maintains that public schools take on the role of perserving class distinctions and passing on the knowledge and values of the upper and middle class Americans. As a result, some children resist school achievement and actually work toward failure to be congruent with their own cultural background.

Erickson (1984) cites the work of a number of researchers who have studied schools and classrooms from a cultural point of view and have found that some 
children are actively involved in failure. A major work in this area is by Willis (1977) in which he studied working class male students. He found that the "lads" he studied were engaged in differentiation. That is, they were joining a group and creating a culture that ran counter to the educational culture of the school. The counter culture was reflected in their hair, clothing, language, speech, and behavior.

The lads did not accept the value of education or teaching.

Where knowledge becomes devalued or worthless, authority, stripped of its educational justifications can appear very harsh and naked. That is why it is opposed. The teaching paradigm is seen more and more in its coercive mode. The total experience of school is something "the 'lads' most definitively want to escape from (Willis, 1977, p.77).

Erickson himself has chided educators who advocate more time on task in educational settings by saying, "Everyone is on task $100 \%$ of the time; the researcher's job is to determine what the task is for each child" (Erickson, 1986). The implication is that each child must make sense of the learning requirements that the school sets out. Resistance to the school's microculture is one way of making sense. "Resistance as an explanation for school failure has been most obvious and has seemed most plausible when applied to high school students" (Erickson, 1984, pp.539-540).

Weis (1985) builds an extensive picture of resistance when she describes the culture of Black, urban students at a community college. While the students perceive the college as an opportunity to move out of poverty, they daily create a student culture that supports behaviors that will eventually lead to school failure for nearly all of them. In addition, student culture interacts with faculty culture that 
focuses less and less on classroom instruction. The faculty see the students as beyond their influence and turn to other interests. This distancing further supports the student culture that sees school success as foreign.

Cusick (1973) produced an insightful ethnographic study of the cultural aspects of one high school. He asked, "What is it like to be a high school student?" (Cusick, 1973, p.1) and proceeded to describe high school culture from a student perspective. Cusick documented how students spent time and how they related to teachers and peers. He found that in the classrooms "a large part of the student's day (is) spent in the state of spectatorship in which he simply watches and waits" (Cusick, 1973, p.48). The energy of the staff was devoted to procedural matters, and the whole organization of the school revolved around processing large numbers of students.

Cusick (1973, p.217) reports nine major socio-cultural characteristics of the high school:

1. Subject matter specialization

2. Vertical organization

3. Doctrine of adolescent inferiority

4. Downward communication flow

5. Batch processing of students

6. Routinization of activity

7. Dependence on rules and regulations

8. Future-reward orientation 
9. Supporting physical structure

These aspects of the school result in compliance by the students. The "organization does not encourage, depend on, or even need one-to-one personal interaction between teachers and students" (Cusick, 1973, p.76). The researcher asserts that since the school itself does not provide interaction or personal involvement then the student's peers must fill that role. "This made it extremely important for students to have friends. In fact, it may have been the single most important thing in school" (Cusick, 1973, p.66).

Cusick (1973) paints the picture of a school that allows students to spend over half their time interacting with their peer groups. The school allows it because the organization demands compliance, not interaction. The students continue it because the peer groups are more rewarding than the school's academic work.

\section{SUMMARY OF THE LITERATURE}

Two bodies of research are of interest in relation to this study of an alternative high school that serves dropouts. The first field includes work on the "incidences, causes, consequences, and solutions" (Rumberger, 1987, p.103) of the dropout issue. Most of the research suffers from lack of definition and attention. Even reports of the numbers of dropouts cannot be compared because different groups have defined dropouts with disparate criteria. Much of the research is conducted after youth leave school and asks causal questions that may only relate to superfical reasons for 
leaving school. The key finding is that the problem of youth leaving school early is significant both in terms of numbers and persistence of the problem.

One area of research represented by Catterall (1987) takes a different approach into investigating the causes of dropping out of high school. The work portrays a process of disengaging from a system in which the youth is unsuccessful either socially or academically. This research complements the second field of re-search, the ethnographic studies of schooling. Erickson and Mohatt (1982) demonstrated that classrooms have different microcultures that affect student success. Cusick's (1973) work showed students dividing their time and attention between academic and social worlds and usually investing more energy in the social world because schools are not organized to deal with individual students and their needs.

The work of Catterall, Mohatt, Erickson, and Cusick suggest that the organization of the school and its interactions is a primary point of investigation. The participants develop microcultures that can be investigated, described, and changed. The culture affects all the school participants and requires a great deal more research than has thus far occurred. The culture of alternative programs has yet to be effectively investigated. It represents a major area of inquiry if educators hope to build understandings of how better to teach students who fail in traditional educational programs.

The following chapter will outline the research conducted at Tri City Alternative Program. It will describe the participant observational research characteristics, state the research questions, and discuss the data analysis. 


\section{CHAPTER III}

\section{RESEARCH QUESTIONS}

\section{INTRODUCTION OF PARTICIPANT OBSERVATIONAL RESEARCH}

In the Handbook of Research on Teaching, Erickson (1986, p.119) describes a number of approaches to conducting qualitative research. He uses the labels "participant observational" and "interpretive research" to include ethnography, case study, qualitative, constructivist, symbolic interactionist, and phenomenolgoical types of work. These methods that may differ slightly are unified by their similar focus and intent. In this style of work, the researcher focuses on the participants in a social situation. The intent is to build "understanding (of) the social phenomenon from the actors' perspectives" (Firestone, 1987, pp.16-17). Many researchers claim they are developing rich descriptions and "social science portraiture" (Lightfoot, 1983, p.18).

Participant observational approaches are becoming more popular in the field of education. Educators have become increasingly dissatisfied with the limits of traditional research (Fetterman, 1984). Teachers point to the mounds of positivist research that try to quantify classroom life by standardizing actions and responses. The result often does not illuminate the issues surrounding teaching and learning. At the same time, a few skilled researchers and anthropologists have begun to study 
the culutral aspects of schools and to demonstrate the usefulness of qualitative research. Wolcott writes that one reason for the interest is because this form of research offers a significant alternative to traditional evaluation techniques. . It provides "a descriptive and interpretative activity whose purposes are to understand rather than to judge and to examine acts of human behavior as part of larger cultural systems" (Wolcott, 1984, p.179). It stresses the actions in a setting, actions as behavior plus the meaning underlying the behavior.

Spindler (1982) writes about the characteristics of participant observational research. First, the observations are contextualized within the framework, and social structure is emphasized. Equally as important is the prolonged nature of the observations. The fieldwork is time consuming and extensive, usually generating scores of notes. Thirdly, the aim of the participant observer is to understand the sociocultural knowledge of the natives by paying close attention to the behavior and communication of the participants. This understanding is viewed as an unfolding process. The researcher allows the interaction to occur rather than predetermining possible responses.

Spindler (1982) goes on to stress two important aspects of the process of this type of research. First, he maintains that hypotheses emerge from the work. It is important that the researcher be knowledgeable about the subject and perhaps even have initial questions to investigate, but the observations guide theory development. The second major aspect is related to allowing the observations to guide the research. It is that instruments should be generated while in the setting. Any survey 
or observational instrument is best designed when the researcher is sensitive to the social environment, not before the investigation when the researcher might be tempted to predetermine or limit responses.

The requirements, then, for participant observational research are demanding. They dictate that the researcher be knowledgeable about the subject but be open to acquiring an insider's perspective. The researcher becomes the primary instrument and relies on observation, communication, and interpretation skills. The amount of time required, and amounts of data generated are massive (Yin, 1984, pp.21-22). Yet, this design is particularly appropriate to the current study.

In the case of social programs that deal with extreme populations, it is often times inappropriate to utilize quantitative designs. In the case of high school dropouts, there is no method of ethically establishing control groups; there is not sufficient baseline data; and the purpose is to study real life programs with all their interconnections (Fetterman, 1984, pp.29-30). The purpose of this investigation and the parameters of the program and population, then, fit into the descriptive or exploratory type of qualitative research discussed by Yin (1984, pp.17-18).

\section{RESEARCH QUESTIONS}

The initial question guiding this study is: What appears to be the distinguishing microculture created by the participants of the alternative school?

This question will guide the collection of data to describe the daily life of the staff and students of the Tri City Alternative Program. The program participants 
have chosen to enter and stay in the program even though they have rejected other forms of education. It is important, then, to know and understand the unique microculture they have created to make the program meaningful to themselves.

The sub-questions are intended to direct the search for a complete description of the interactions and the meanings of the interactions created by the participants. The goal of participant observer research is to make known the hidden meanings of the microculture. The sub-questions are:

1. What types of interaction produced by the microculture occur in the alternative school?

2. How do the environment, the instructional modes, and the program structure reflect and are reflective of the culture?

3. What meanings do the participants attribute to the interactions produced by the microculture?

In participant observational research, the questions are beginning points to give the researcher focus and the latitude to investigate new areas or questions as the project progresses and patterns develop. Erickson (1986) describes this as "crocheting back" the research questions. That is, as the research proceeds, the researcher goes back, checks the question, builds on it to see if the question still seems appropriate, and goes on to pick up new data and possibly formulate new questions. 


\section{DATA COLLECTION AND ANALYSIS}

There were five major sources of data collection for this research:

1) Interviews. Interviews were conducted with both staff and student participants.

The interviews were of two types. The structured interviews posed the same

questions to all participants. The open ended interviews were conducted as

situations permitted and followed a pattern of directing the questions based on the participants' responses. Twenty students and four staff were involved in structured interviews. An additional twenty students were interviewed as they participated in the program.

2) Observations. The program observations were made during regular program operation and were conducted over extended periods of time to include all program components. Four days of program operation were videotaped; selected components were audio taped. All were recorded with field notes. The observations extended over a two year period.

3) Student projects and work. Work produced by the students was collected and analyzed. Some of the work was regular assignments such as writing topics about the students themselves and the school. Some of the work was specially designed for this research. For example, when studying communication skills, one group of students learned interviewing techniques by interviewing fellow students about their participation in Tri City Alternative Program (TCAP).

4) Staff meetings. Field notes were made of selected staff meetings. At some of the meetings, the researcher added agenda items that related to the research 
questions. At other meetings, she audio taped the discussion to record the natural conversation that occurred among the staff. The agenda and discussion from thirty staff meetings were studied.

5) Program materials. Program materials were collected and analyzed. These included curriculum materials, program reports, and instructor observations. I analyzed six quarterly program reports, one third party evaluator report, sixty instructor evaluations, and forty-five program evaluations.

Because data come from so many sources in participant observations, its collection and analysis is extremely complicated and time consuming. The basic tool is the field notes. I used a system of making field notes that included descriptions of time, setting, environment, and interactions. As I conducted more observations and wrote more field notes, I started to see behavior and interactions recurring. I started noting these in the margins of the notes and going back over old notes to mark and identify patterns.

As patterns became more obvious, I made separate notes and started collecting them along with possible interpretations. At this point, I also started looping back to check some of my questions and interpretations. For example, when a student project pointed to unique types of interaction occurring at TCAP, I included questions about these interactions in student and staff interviews.

This looping process was also crucial in checking for researcher bias. When I thought I had identified a pattern of behavior, I would check back to other sources to see if the pattern held. For example, if an instructor made an observation to me 
about the importance of humor in the program, I would check the student produced evaluations, the field notes from observations, and the interviews of other participants to see if I could verify the existence of multiple sources pointing to the value of humor. Thus the data is "cross-checked for validity with what has been learned from other sources" (Lazarus, 1985, p.40).

When I had collected enough data to demonstrate patterns and describe the TCAP microculture vividly, I checked it with the participants by presenting to them the descriptions and interpretations. This was the last step in checking to see if the results reflected the meaning attached by the participants.

The next chapter will lay out the description of the microculture and environment of Tri City Alternative Program. It will include the evidence gathered from all the data sources and the interpretation made of the different cultural elements of the program. 


\section{CHAPTER IV}

\section{DATA AND FINDINGS I: PROGRAM STRUCTURE AND CONTEXT}

"Rather than conceiving of culture as a given, it is seen as produced in particular sites" (Weis, 1985, p.x). In order to answer the question, "What appears to be the distinguishing microculture created by the participants of the alternative school?" I analyzed the data generated from my fieldwork to find themes and patterns in the program operation and the participants' behaviors and interactions. I looked at how the staff and students spent their time, what they talked about, how they explained the program to outsiders, what they paid attention to, and what they choose to change or not change. The resulting findings are organized into categories describing the program structure and the participant interactions.

I will first describe the structural elements of the program: the physical setting, the daily instructional schedule, and the non-instructional daily schedule. Particular attention will be paid to those parts of the structure that constitute the context for the behaviors of the participants and that reflect cultural beliefs of the participants so that the outsider understands the context of the actions happening within the program.

The next chapter will describe the interactional elements of the program's microculture. The structure (context) and the interactions (behavior) are presented 
separately because of the extensive amount of material that was collected and analyzed. They cannot, however, be kept absolutely separate or distinct because as the students and staff lived their everyday lives at Tri City Alternative Program, their actions were influenced by the program structure, and the program structure influenced their behavior. The interpretation of the data will show the microculture of TCAP as defined by the elements of both structure and interaction and will paint the picture of the microculture as it is lived on a daily basis. A microculture is a group of people who interact on a regular basis. Erickson (1986) uses the term to describe those groups that are typically the focus of qualitative researchers. It could be a family, a classroom, or an office. The task of the researcher is to find patterns in the behaviors of the participants and to make explicit the patterns and the meanings of the behaviors.

\section{THE STRUCTURE OF THE PHYSICAL SETTING}

Tri City Alternative Program is operated from the second story of an 80 year old building in downtown Oregon City. The building and its surroundings suggest the area has seen more prosperous times, but now many of the store windows are empty or sorely neglected. The school's entrance is a plain glass door that opens to a stairway. After climbing the stairway that turns twice, a visitor faces a plain brown door with a small, hand lettered sign, "Tri City Alternative".

After entering the school, one finds a contrast to the cold downtown and the nondescript entrance. The old building provides an interesting space with seven foot 
high windows, twelve foot ceilings, steam radiators that clank when starting or stopping. The school itself contains two large classrooms. One with an upholstered couch, bookshelves filled with paperbooks, and four rectangular tables with student chairs pulled around them. The other is slightly larger; it contains six tables arranged at various locations and angles in the room. This classroom contains more evidence of the school's activities: a perfect attendance chart, a challenge board of activities, a blackboard filled with the week's schedule, a computer sign-up, and other field trip information sheets.

Directly across from the smaller classroom is the student lounge. It is easily distinguished by its Pepsi vending machine, couch, three easy chairs, and cigarette filled ashtrays. Beside the larger classroom is the reception area with the secretary's desk and shelves filled with books, papers, first aid supplies, and other materials for student and teacher use.

Down a short hall from the reception area, there are three doorways. The first on the right is the instructors' office. The small room is packed with three desks, phones, file cabinets, and numerous chairs. Opposite the office is a large closet like room labeled "Materials Room". It holds a file cabinet, shelves, tables, and storage cabinet all filled with student books and materials. The room is neat even though is obviously well used. The last door leads to a room that doubles as a workroom and overflow classroom. It has student tables and chairs along with a ditto machine, paper cutter, and more file cabinets. Figure 2 outlines the floorplan and shows the major furniture layout. 


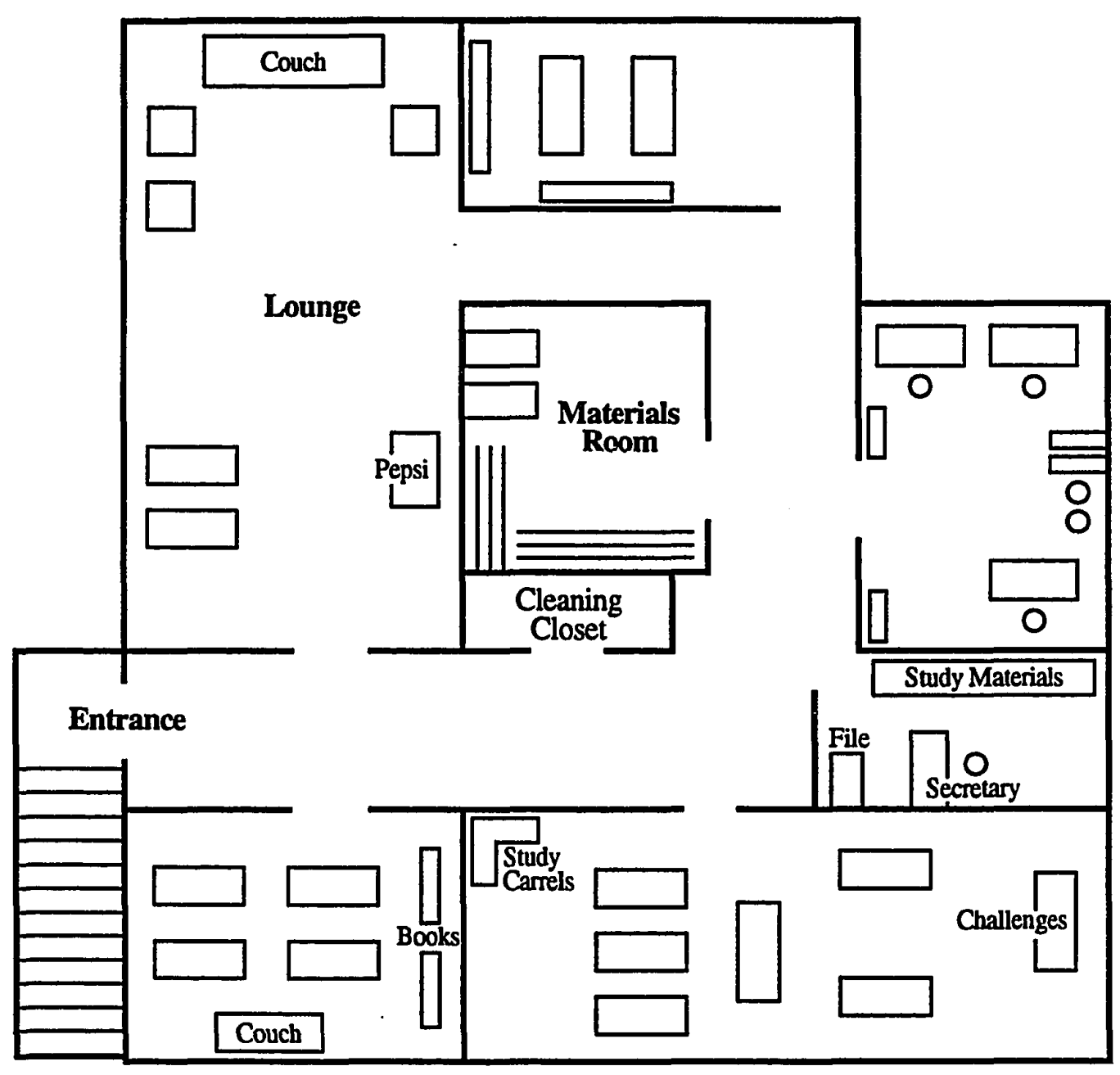

Figure 2. Tri City Alternative floor plan. 
On the whole, the area has some of the trappings of a school but not the feel. There are no bells, long hallways, lockers, cafeteria, gym, or campus of any type. The walls are covered with rustic "barn wood" or old wallpaper. Nearly every surface is covered with student work or program information. Some of the displayed materials and boards are shown in Figures 3, 4, and 5. The ones shown are the displays that remained on the walls throughout the school year.

In regard to the physical setting, the staff spend time and attention on a weekly and sometimes daily basis adding to the student display boards. Students' names and pictures are displayed in no less than three places on the walls, and the recognition boards for attendance, testing, and graduation add to that number. There are displays of pictures of students participating in field trips, guest speaker lectures, and other activities.

The displays that stay up all year long are the ones related to expectations. The attendance board, the job board, the list of attendance points are not only used for the entire year, but are also used from year to year. There is no evidence of athletics or socials events such as dances. There is also no graffiti or destruction of property in sight.

\section{THE DAILY INSTRUCTIONAL SETTING}

The typical day at Tri City Alternative begins around 8:00 am when students and staff start arriving. The staff immediately start preparing for the day: taking 

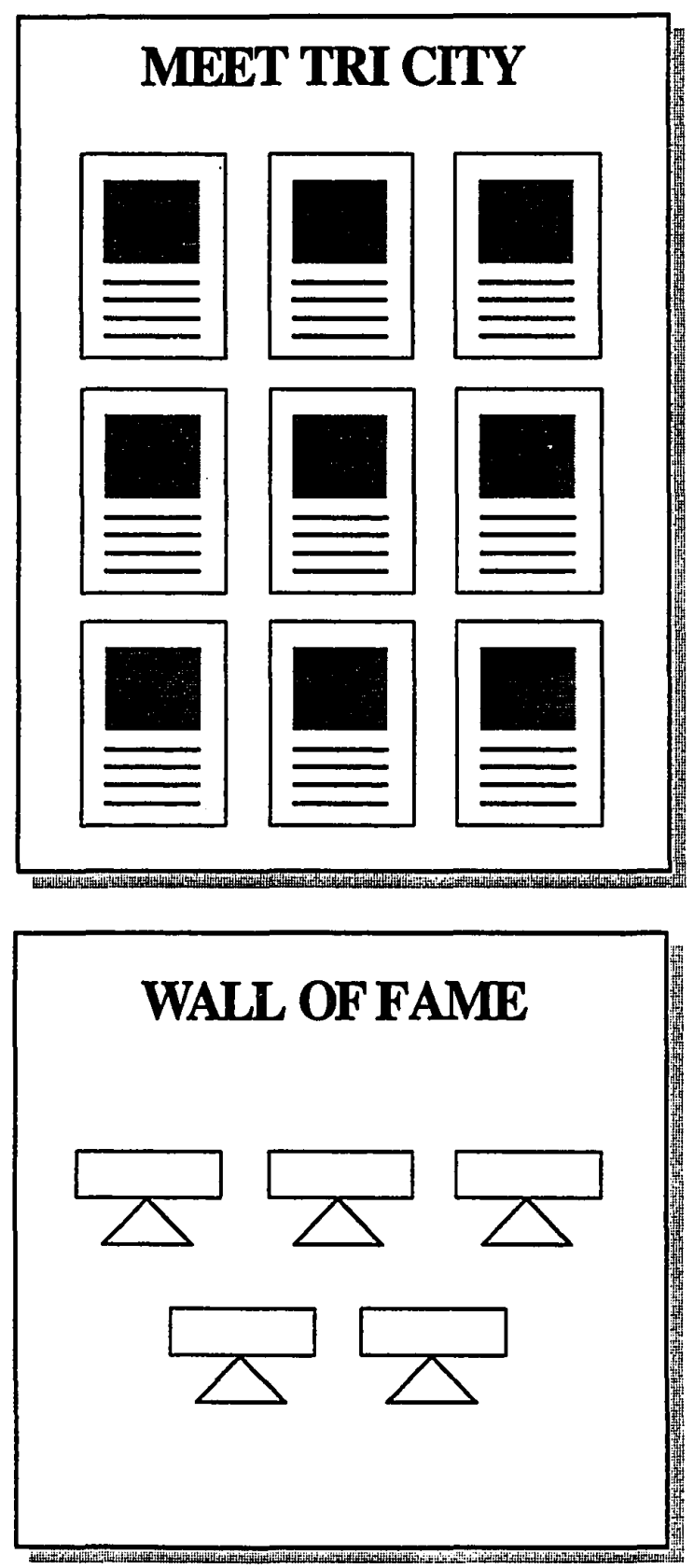

Figure 3. Student attendance and graduation boards. 

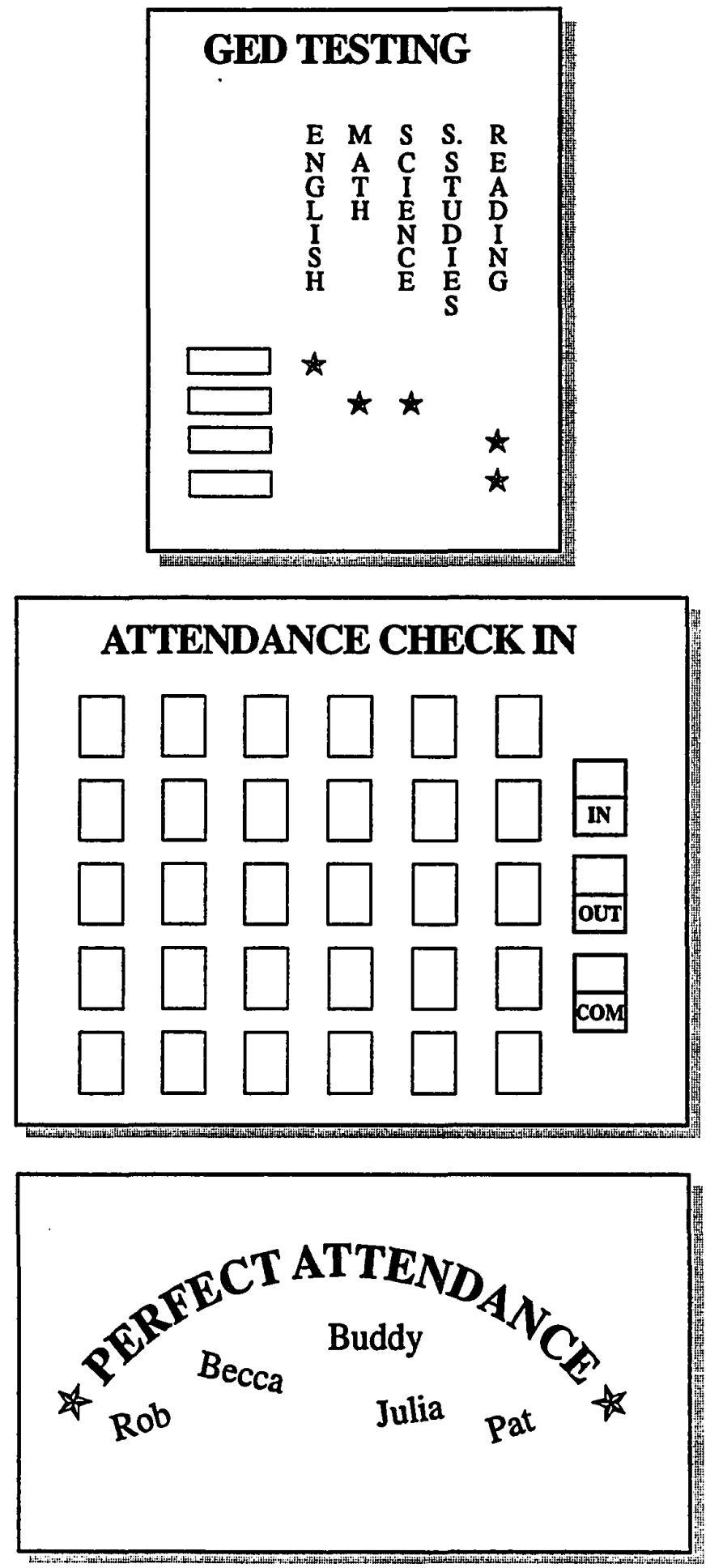

Figure 4. Samples of display boards. 


\section{Challenge Yourself}

Make an "ice cube

keeper" that can

keep ice from melting

as long as possible!

Figure 5. Sample of student work directions. 
phone calls from sick students, putting out needed materials, catching up on paperwork. They seldom sit at their desks; they can be found in any room of the school, talking with other staff and greeting students as they arrive.

The staff is comprised of two instructors and two teacher assistants. One teacher assistant is responsible for the majority of the secretarial jobs, including answering the telephone, keeping attendance records, preparing instructional packets and materials, and maintaining files. The other teacher assistant works in the classrooms as a tutor for students and an aide for the teachers. The two teachers are community college faculty. They both have Master's Degrees in Education and have a history of teaching in elementary schools before teaching at Tri City.

The students seem to arrive one or two at a time, being transported by public transportation, family, bicycles, or walking. As they enter the school, they usually go directly into the lounge to smoke and to talk to other students until the official beginning of school.

The students range in age from 15 to 18 years. They come from high schools throughout the county. The program records show that all of the county's ten high schools are represented by the student body which numbers thirty students at a time. In addition, at least three other out of county school districts have one to two students per year in the program. A total of seventy-five to eighty-five youth attend the program during the course of one school year. The students have one thing in common; they have not been successful in traditional high school. They call themselves "dropouts" or "kickouts". 
At 9:00 school begins with a class meeting. The instructors move through the various rooms saying, "It's 9:00; time to get started" and "Let's go". With no verbal response to the instructor, the students begin putting out cigarettes and slowly walking into the large classroom.

Students continue to talk to each other when they are seated in the large classroom. They are scattered around the room. Some are sitting at tables; others pull chairs to a spot and sit down. There is no formal seating arrangement or plan.

After all the students are seated, one instructor makes a comment like "O.K. Let's get started." She then waits until the student conversation dies out. The class meeting proceeds with mostly teacher delivered instructions. The instructor explains items written on the blackboard. They consist of field trip arrangements for the following day, a film to be shown on Friday, and ideas for journal topics. The instructor carefully outlines which items are required for everyone and which are individual choice activities.

Every morning seems to begin the same way. Instructors review some of the same information from the day before and adding new explanations or items. When students become distracted, one of the instructors walk near that student or the speaker stops until the student's attention returns to the speaker. The informal seating of these group meetings seems to work well for this type of subtle moving around the room and redirecting of attention.

Student involvement in the class meetings generally came in two ways. Group problem solving activities were conducted. One example of this was a morning in 
which the instructors were introducing a new unit idea about personal health issues. After the usual announcements, the instructor handed each table of students a large piece of butcher paper that had lines dividing it into fourths. She asked the students sitting away from tables to join one table. They pulled their chairs up, often causing crowded conditions at the table. In each quadrant of the paper, there was one label (either alcoholism, rape/incest, abuse, or drug addiction). The instructor then said, "I am going to give you 15 minutes to write down all of the facts, myths, beliefs, and misunderstandings you have ever heard about each of these topics. It doesn't matter if you know it is true or not. We want a list of all the things you have ever heard beause some people may believe them. During this unit we will try to sort out which ones are true and which ones are false." For the next fifteen minutes, the instructors circulated around the room but interacted only if the group seemed off task. Each group began working with one or two people writing on the paper and the other students either telling them what to write or reacting to something already written.

At the end of the group activity, the large pieces of paper were hung on the walls around the large classroom. For the next four weeks during each class meeting, the instructors referred to one of the quadrants by passing out and discussing information, talking about a speaker coming in to address the topic, introducing a movie, or building some other teaching mechanism related to the topics. 
The second way students became involved in the class meetings was student initiated. During a class meeting, one boy spoke up and said, "I think we have a problem that we need to talk about because it is making me real mad." The instructor asked, "What is it?" and the boy replied, "Clean up. I'm getting real tired of cleaning up the lounge after people have acted like pigs and made a mess with cigarettes and food." At that point several other students agreed with the boy and gave examples of people leaving their "junk" for others to put away.

This discussion lasted about ten minutes with the instructors having limited input by saying things like "What should we do about it?" and "What are options to solve this?" The interaction ended with one girl saying that everyone should remind each other to clean up after themselves and to talk about it again if it got worse.

After the class meeting ends the students pick up individual work folders and find a work area in one of the classrooms. Most sit with others at one of the large tables; only a few choose to sit at a table or carrel that is isolated from others. As students get out the individualized work contained in their folders, they talk quietly among themselves; parties, friends, and home problems take up much of this conversation.

The instructors are occupied directing students to work or checking on individual assignments. Typically, the instructor sits down at a table of students and starts to work with one or two students at a time. "Let's work on your goal sheet" is one comment heard over and over again. It initiates a conversation between the instructor and student about a student planning form that is used to project work to 
be done. Some students use daily goal sheets that are filled in every day for the work to be accomplished that day; others use weekly goal sheets. Examples of the goal sheets are found in Appendice A and B.

As the instructors talk with each student about the goal sheets, they also correct work that has been completed and give assistance on work in progress. There are numerous personal comments about life outside school: "How is your job going?" "Did you turn in those applications yet?" In one conversation, an instructor was talking to a student about her plans to continue her education after achieving her GED. The student put her arm around the instructor's shoulder and said, "You will really miss me when I'm gone from here." The instructor replied, "I know. I have trouble thinking how we will carry on!" There were smiles and a feeling of good hearted teasing.

The day proceeds with students working on learning packets, computer programs, and self paced materials. The instructors and teacher assistant move slowly and purposefully around the school, interacting with students and each other. When one or more students appear to be distracted or not working on school work, one staff member walks up to them and says, "Let's see your goal sheet and what you're working on."

Lunch is scheduled from 11:00 to 12:00. The students come and go during the lunch period, ususally eating at a fast food restaurant or convenience store. The staff usually eat food brought from home. They sit in the office or a classroom often correcting learning packets, as they eat. 
The end of the lunch period is signaled much the same way the beginning of school is signaled. Staff go from room to room and say, "Time to start quiet reading." Quiet reading lasts for thirty minutes. It is marked by no talking by anyone, staff or students. Everyone reads. There are people reading newspapers, magazines, paperback books, and textbooks. During staff interviews, they each identified quiet reading time as their "favorite time of the day".

There is no signal at the end of thirty minutes of reading. Several students consistently check the clock as the half hour mark nears. They are the first to put away their reading materials, begin to talk and move.

The next part of the day is the same as the morning work time. Students are working to accomplish their goals. Staff are working with individuals and small groups of students who may all be needing the same instruction.

Fifteen minutes before time to dismiss school, someone, usually a student, starts saying, "Clean up. Time to clean up." This is a time when everyone seems to be moving at once. Students check a small board near the secretarial desk that has clean up jobs and their names assigned to those jobs. The jobs range from wiping off the tables to cleaning the restrooms. Every student has a job, and no one is dismissed until the instructors walk around the school and declare, "All clean!"

There are two important aspects of the instructional schedule and structure that are particularly noteworthy. First, there is a lack of subject matter specialty. The staff presents topics and themes; the basic skills are taught by all staff. Researchers such as Apple (1978) maintain that subject and curriculum specialization reinforces 
an elitist view of knowledge. This position would stress that traditional organizations of schools put more value on some types of learning and communicates to students that they are in an inferior position when it comes to learning. The converse of this is true at Tri City Alternative. Subject matter is not compartmentalized; staff are not specialized, and students are seldom placed in a lecture type format.

The second aspect has to do with the use of time. Socialization and learning happened within the same instructional schedule. There was little to distinguish one part of the day from another. Cusick (1973) studied high school students' schedules and activities. He found that students had little or no interaction or socialization time in classrooms but spent great amounts of time and energy outside classrooms satisfying their need to interact.

Students at Tri City talk and visit with other students and staff while they are working. They are able within broad parameters to decide when they will work on specific assignments, where they will sit, when they will take a break, and when they will ask for staff assistance. Because the structure allows for flexibility, the program provides elements that Cusick maintains high schools deny because of the traditional organization: "a degree of independence and power over their activity...and...the immediate pleasure of participating in human interaction" (Cusick, 1973, p.214). 


\section{OUTSIDE THE DAILY INSTRUCTIONAL SCHEDULE}

The instructional time of Tri City Alternative Program consists of twenty hours weekly in which the staff and students interact as described in the daily schedule narrative. In addition to that schedule, there are three other components of the program schedule that must be discussed to fully describe the program structure. The staff spend an additional fifteen to twenty hours per week engaged in these three areas: interviewing students, conducting staffings and staff meetings, and counseling and advising students. In other words, there is almost an equal amount of staff time devoted to out of the classroom elements as there is to the in class elements.

Interviewing Students

Interviewing students occurs one to two afternoons a week. Students who want to attend Tri City are scheduled for an interview. When they arrive at the school for the initial meeting, they are given a standardized reading test and a teacher developed sentence completion sheet (sample in Appendix C). After finishing the reading test and writing sample, the youth talks with one of the instructors. The instructor conducts an interview and fills out an interview form (sample in Appendix D). Most of the talk from the instructor has to do with how the school operates and what the expectations are. The instructors say the interview is important to let the students "know what the boundaries are before they start." 
The student is told "you have to choose to come to Tri City and we have to choose to accept you." However, the program records reviewed for one school year revealed only two students were told they could not come to Tri City. The rest, seventy-four youth, were told they were accepted. Of the two not accepted, one was referred to a special education program, and one was not accepted because he had a history of arson.

When asked about the value of the student interviews, the staff all said they were "too valuable to give up". Instructors and teachers assistants described them as key to helping students get started in the program, not as screening mechanisms. The interviews are used to assess strengths and weaknesses "so we don't ask them to do something that is difficult or impossible for them when they first come". The staff also related how they used the interviews to develop programs strategies. They referred to the questions on the interview related to past school performance and said that they get a large number of responses from students who have trouble succeeding in traditional high school programs. "I have trouble going to seven different classes" and "There is no one in the high school to help me" were responses the staff felt indicated students who needed a program structured differently from most secondary schools.

The students who spoke about the interview process expressed surprise that they had to go through a screening to be accepted. One student confessed she "was really scared and nervous, but then again I really wanted to get back in school" so she went through the interview. 


\section{Staffings and Staff Meetings}

Staffings and/or staff meetings receive time and attention everyday. At the end of each school day, the four staff members conduct what they label as "staffings". Frequently, they sit in the office. Sometimes they sit in the large classroom if they are working on calendars or other materials. Each instructor has a list of students for whom she is responsible to oversee their progress. The staff call this their "caseload". The instructors look over their caseload list and make comments about each student. The other staff members add comments about what they observed the student doing or what they think would help the student achieve better. There are always students who receive more discussion time, usually because they are not completing work, because the staff have concerns about them, or because there has been an incident needing attention.

In addition to the discussion of individual students, the staff spends time talking about the next day's or next week's activities. The instructors relate that teaching the basic skills "is the easy part". It is the part of the program accomplished by packets and materials. The staff spends the majority of their planning time focusing on themes which include field trips, guest speakers, and morning group activities. They say these are valued because they allow students to learn in different ways and to find "lots of ways for students to succeed".

The staff meetings are held every two weeks for two hours at a time. At these meetings the program staff interact with college staff working at other alternative programs sites. During the course of this study, the department grew from eight 
members to twelve then to fourteen. The staff meetings remained constant with some unique features. The staff rotated the role of facilitating the meetings. Everyone had an opportunity to add agenda items. There was always time devoted to "program updates" which was a time staff used to tell about students in their programs, field trip successes and failures, problems they were struggling with, and other developments since the last staff meeting.

In addition to the department meetings, the program staff spend two to four days twice a year at a staff retreat. The retreat is generally held about one hundred miles from Oregon City, requiring the staff to stay overnight, to plan meals together, and to be together for extended periods of time. The retreat agendas show time spent on recognizing achievement, planning for the future, and problem solving current issues. At the retreat, staff have computers, typewriters, books, and other curriculum materials. They have produced pre-employment training packets, attendance procedures, current event reading assignments, creative writing assignments, and art exploration activities at retreats.

All the time that the staff spends together working collectively is an element Sarason (1971) sees missing in traditional schools, and it is one he maintains is essential in order for educators to successfully improve or change schools. $\mathrm{He}$ observes "no vehicles of discussion, communication, or observation" in traditional schools and states, "What is not recognized or verbalized cannot be dealt with" (Sarason, 1971, p.78). 


\section{Counseling and Advising Students}

Counseling and advising students takes place both during instructional time and outside school hours. It is discussed in this section because it is not part of the planned schedule of the program. Indeed, the staff said they had never expected to spend so much of their time counseling students. One instructor said it made her a little nervous because she was not a trained counselor but had come to see it as part of working with "high risk youth". There were numerous discussions during staff meetings and among staff members about getting additional training to deal with emotional isssues. Several inservice opportunities were planned by staff. One involved a psychologist coming to two staff meetings to discuss how to deal with suicidal youth. Another involved one half day of training about drug and alcohol involved youth.

One incident with a student started at the end of the school day and lasted for an hour after the other students had left. The student sat in the office with the instructor. She was crying and saying, "I'll just leave home. That will be easier for everyone. I just can't take this anymore." The instructor was talking very quietly and asked, "If you left home, where would you go?" The student replied, "I don't know. I could find a place. I could stay with friends." The instructor replied, "I'm real concerned about you making plans when you are so upset. I'm afraid you might choose something that is worse for you in the long run than staying at home."

The instructor continued to question the student about her feelings, and the instructor gave her opinion about running away not being a good choice. The 
interaction ended with a plan for the student to go home and talk with her mother about counseling options. The instructor said she would talk with the mother about those options when she called.

When the Tri City Alternative Program staff accept the counseling aspects of the program, they operate in an area many teachers feel is outside the responsibility of the school. Frymier and Gansneder reported that teachers felt comfortable with basic skills and thinking skills, but they felt the student and parents should be "responsible for students' daily attendance, listening, attitude toward school, completion of homework, general behavior in school, and attention in class" (Frymier and Gansneder, 1989, p.145). More than 60\% of the teachers surveyed said that teachers could not help high risk youth deal with the types of out of school problems that TCAP instructors were observed dealing with (Frymier and Gansneder, 1989).

This chapter began to paint the picture of Tri City Alternative Program. The setting and the schedule describe how the participants spend their time and how the environment contains evidence of their microculture. The next chapter will describe key patterns of interaction that are carried out in the environment. 


\section{CHAPTER V}

\section{DATA AND FINDINGS II: PARTICIPANT INTERACTIONS}

The program structure is the context in which the students and staff engage in their everyday life at Tri City Alternative Program. Chapter IV described that context through the elements of the physical setting, the instructional day, and the non-instructional schedule. This chapter will look at the elements of the Tri City microculture that are enacted by the participants through their interactions. As the students and staff of Tri City interact, they attach meanings to those interactions, and they develop patterns of interactions and meanings. The patterns have evidence in the physical environment and in the actual social encounters of the participants. It is these patterns that define the program's microculture. It is these patterns that allow the participants to engage in activities and place value and meaning on the encounters.

I use the term context to include those aspects of the microculture related to the physical environment and the program organization. I label interactions those behaviors that happen among the participants: student to student, student to teacher, teacher to teacher, student to outsiders. In describing both the context and interactions, it is necessary to state the meanings and the values placed on those elements of the microculture by the participants. 
There are four major elements of the interactions that emerged as keys to understanding the microculture of Tri City Alternative Program: clearly stated expectations, staff and student attention to culture, sense of caring and defining competence, and sense of humor. All of the elements are related to the program structure described in the previous chapter. Each of the patterns have evidence of its existence in the physical environment or in the time schedule of the participants.

\section{CLEARLY STATED EXPECTATIONS}

Sarason's work in schools led him to conclude "the intended outcome is rarely stated clearly" (Sarason, 1971, p.3). He points to a lack of discussion about expected behavior, ways of problem solving, or even expected skills to be learned. This causes confusion among teachers and students alike. The data from observations and interviews at Tri City Alternative illustrate a very different picture of communicating expectations. Attention to and discussion of student and staff expectations receive a large share of instructional and non-instructional time. Expectations were both verbal and written, and the participants expressed very similar understandings of the program expectations.

There are structural elements of TCAP that clearly communicate expectations. The environment contains charts (refer to Figure 3) highlighting attendance performance and requirements. The student entrance interview (refer to Appendix D for form) focuses on expectations and asks youth to decide if they are willing to live up to the expectations. Every student has a goal sheet (refer to Appendices A and B 
for samples) with work listed daily or weekly. The staff speak of clearly communicating to students what is to be done. They have developed every curriculum component with a checklist (refer to Appendix E for sample) that lists every assignment with a check off section to indicate completion.

The element of the microculture that was particularly illuminating about expectations was the commonality in language used by the staff. Instructors and teacher assistants were all observed interacting with students using very similar words or different words with the same message. Students who needed to be redirected to work were asked, "Show me your goal sheet. What do you need to be working on?" It was a familiar refrain no matter which staff person was being observed.

There were frequent discussions during staffings focusing on how to deal with a particular student. Staff would share strategies that worked or did not work. They would often come to an agreement to use a new intervention with a student, and all the staff would act consistently.

This commonality of language was observed when students showed visitors around the school. In watching one student explain the program to a stranger, an instructor commented, "The students are more specific than we are!" The student spoke of "expectations", "requirements", and "responsibilities".

While studying students in classrooms, Erickson (1984) observed that when there is conflict students start using language, dress, and actions to resist teachers, but when there is no conflict, students begin to model their language more and more 
after the language of the teachers. Weis (1985) and Willis (1977) found the same dynamic in studying other school microcultures. When there is resistance to education, students will develop their own, contradictory values and behaviors about elements such as language and use of time.

\section{STAFF AND STUDENT ATTENTION TO CULTURE}

During the course of this study, not one of the participants used the term "culture" or "microculture", but there seemed to be a cultural perspective on' the part

of the staff. That is, they demonstrated an awareness that the group forms patterns, that the environment impacts the group, that group interactions had impact on the participants. The staff spoke of "creating our own world". They told of the advantages of working in a self-contained, off-campus program. They talked of the group of students as "jelling" into a cohesive unit.

Cusick (1973) and Catterall (1987) illustrated two microcultures existing in schools: an academic one and a social one. Cusick's ethnographic study portrays students forming their own microculture because the academic arena of the school did not allow for interaction, initiative from students, attention to individuals, or awareness of student concerns.

There is a clear effort and value placed on integrating academic and social arenas in Tri City Alternative. The staff talk about teaching both academic and affective skills. One member said, "Teaching the basic skills is the easy part. Addressing the emotional and social issues is what keeps us challenged." 
Not only did the students state that they were happy at Tri City, the staff often discussed what they found satisfying about their jobs. During one staff meeting, the discussion turned to comparing the attitude of the program staff to other instructors. One instructor commented that she liked to work at Tri City because no one ever said, "It's not my job." The teacher assistant added to the conversation by saying that she had never worked anywhere else where the staff saw the program as a whole and everyone pitched in to get the job done.

There also seems to be an understanding on the part of the staff that there is a dynamic similar to resistance theory. When Erickson (1984) and Weis (1985) described examples of resistance, they showed students who chose school failure as a way to make sense of their own cultural identity in opposition to the school's expectations. Staff talked about a pattern they often saw with students. When the student started feeling comfortable and making progress at TCAP, there would be some special praise or reward given to that student. The staff then "just hold on because oftentimes we see students acting out right after we give them a pat on the back." The staff had discussed this observation and had come to the conclusion that their praise was seen by some students as contradictory to the student's self-image (as a failure) that had been built in traditional schools. They attributed the acting out as a reaction some students might have to resolving conflict about their changing self image. They felt the school was offering a new self image that the student had to decide to accept or reject. This seems to be a parallel explanation to Weis' 
observation that "Success there involves a break from the collectiviy, and a willingness to adopt a new cultural style" (Weis, 1985, p.120).

To look at the student perspective, I designed a student project as one way to gather student views of the program. During a communication unit in which each student was to volunteer for one of five different group projects, I labeled one of the group options "An Anthropological Study of TCAP". The other options included writing a newsletter, developing advertisements, making a video, and designing art. I introduced the study option by asking if anyone knew what an anthropologist did. There were no responses so I explained that they studied different societies, and if anyone wanted to study TCAP, they should sign up. Five students chose that option.

During the first group meeting, I explained that anthropologists often go to tribes or other groups to study things like "eating habits" or "family life". I drew a comparison to the National Georgraphic specials they saw. I said scientists are trying to explain to us what life and customs are like in other cultures. Our group would now function as anthropologists and study the TCAP tribe.

I explained that the group should decide on one aspect of TCAP that was important and that they thought outsiders should know about. The group brainstormed possible areas of study. They listed learning, class meetings, breaks, friendship, field trips, interactions, social groups. Several students suggested friendship would be a good project, but one student said interactions would be better because it would include friendships. The rest of the group agreed. I gave the 
students a Polaroid camera and a tape recorder and told them to plan how to study interactions and to find a way to represent it to others.

First the students took pictures of people in the school. Some of the photographs were staged; others were candid. They organized the pictures on a display board and added labels to each one. One photograph showed a teacher and a student sitting at a classroom table. The label said "Teacher and student working together". Another one pictured two students working together on a computer simulation game. The group labeled it "2 students interacting". One photograph that was staged for this project showed three girls feeding donuts to a fourth girl. It was labeled "Interacting with donuts".

Next the group turned to interviewing other students. They wrote five questions which they read individually to ten different students. The questions were:

1) How do you feel about how people relate to each other at TCAP?

2) Do you think people at this school have a different attitude than at public school?

3) Do you think people here relate better than in public school?

4) When you first came to TCAP, how did the other students treat you?

5) Do you like to work closely with the instructors?

The interviews were tape recorded. All five students in the group listened to the recorded responses. Then they wrote a conclusion that they added to their display board of pictures. The group's conclusion was: 
What We Learned About How Students Interact at Tri City

We learned that students at Tri City relate better with each other than in public schools because Tri City is a lot smaller with less people where you get to know one another pretty well and everybody has basically the same goals to get their GED or high school credits and make something of themselves. Everybody is just like one big family.

This attention to the group is an especially striking element of Tri City

Alternative Program. As Sarason points out, "Individuals learn but always in a social context" (Sarason, 1971, p.197), and he goes on to stress that many of our educational perspectives have been built on the basis of psychology of the individual. Researchers and teachers alike would be better served to consider the individual in the cultural setting, affecting and affected by the group.

\section{SENSE OF CARING AND DEFINING COMPETENCE}

"I never thought I would be working with high school dropouts, and now I can't imagine I would ever enjoy anything else as much" was a comment made by an instructor that reflected a sense of caring demonstrated by the program staff. Most lists of essential alternative program components include a reference to a caring staff (Wehlage, 1983; Mann,1980). This could mean that the staff choose to teach in the alternative program or that they have special skills or talents that are essential to the program. By finding evidence and descriptions of caring, there can be a better understanding of how a sense of caring is enacted at Tri City Alternative Program. 
Clearly, one element of caring at Tri City is related to the integration of social and academic concerns discussed in the previous section. The written student evaluations of teachers are full of comments about caring: "The students need her help and she is very understanding to the way people feel." "She listens to everything from family, work and school problems to complaints and praise. If I ever have a problem, she gives me options, alternatives and advice." "I feel she enjoys her job, which makes it enjoyable to be here."

There is another element of caring that is in existence at Tri City Alternative Program, but it is more subtle and woven into the fabric of the program. It has to do with how the staff define competence or, rather, how they re-define competence to be more inclusive.

During one staff retreat there was a long discussion beginning with questions about how to increase reading and writing skills. The staff gradually broadened the discussion to communication skills, including reading and writing with speaking, listening, questioning, drawing, graphing, etc. Near the end of the discussion, one instructor summarized the conclusion by saying, "We may not be able to make all these kids excellent readers and writers, but we can make them excellent communicators."

The staff over the years have built in numerous opportunities for students to build communication skills. The pictures and interviews displayed prominently on the "Welcome to Tri City" board are the result of first day interviews. Every student is paired with another student on the first day of attendance. They are shown how 
to interview each other and how to produce a paragraph about that person to accompany a picture they take. Every field trip has at least one student acting as the photographer to record and later to make a display about the trip. When the program purchased its first video camera, students added that medium to their communication repertoire.

The following comments were taken from one instructor's student evaluations: "Although she has a good knowledge of spelling, she does not make a student feel that this skill is impossible to learn. She is open to using more than more avenue to learning." "She has pushed me to where I am today. I wouldn't be this far so fast without her support and help as a teacher and friend." "I like that she puts feeling into what she does." "I feel she enjoys her job, which makes it enjoyable to be here."

Visitors are greeted by students who have the responsibility of taking the visior on a tour and explaining the program. Students become very adept at acting as guides and discussing their own experiences. Often times the visitors are given glimpses of students who are seeing their competence in a very different way from the way they saw themselves in high school.

On one occasion, a visitor walked in the door, one student stood up, walked over to him, and said, "My name is Rob. I'll show you around."

The two walked into every room of the school. Rob would explain what activities occurred there. He picked up his work folder and started showing the visitor his work and goal sheets. Rob said, "Some people are on weekly goals, but 
I'm on a daily schedule because I don't work fast. I'm slower than most people." The visitor asked, "You mean it takes you longer to finish the same things?" Rob responded, "Yes, I have to work real hard because when I came here, I was reading at the third grade level, but now I have worked up and I have finished three of my GED tests." The visitor said, "You don't talk like you have a reading problem." Rob answered, "I don't anymore!"

This type of re-defining learning and competence seems to be an example of Erickson's (1984) scaffolding. Through social relationships and bridges from one learning to the next, the learner is able to take charge of his own learning.

\section{A SENSE OF HUMOR}

While it is difficult to describe humor and its importance, its existence was referred to again and again by the participants. On a student evaluation of the program, one comment said, "What I like about (instructor A) is that she is a funny person to be around." There was good natured teasing between staff and students. During one student interview, the student leaned over to me and said, "Act like we're talking about (instructor B). It drives her crazy!"

The staff often commented on the amount of laughter and humor that existed in their interactions. They retold favorite stories about each other and students. During one staff retreat, the group was listing program values to relate to new staff members, and one of the first values mentioned for inclusion was "humor". 
During interviews with the staff as well as during observed staff meetings, the teachers would describe their humor as "black humor". They said they needed to laugh together in order to release some of the tension involving serious student problems. Other instances of humor were valued as story telling. Staff retreats often involved staff members retelling the same story from the retreat before. These stories became part of the community and tradition of the group.

The humor displayed was good natured. In talking about the interview process, one instructor spoke to a group of teachers from another program. She said that even when she believes a student would benefit from attending Tri City, she allows the student to make that decision. She said that after telling a young person about the program, she says, "If that is not what you want to do, then maybe you'll be older later." It was a comment that received a few seconds of silence then laughter at a very nonjudgmental posture.

Story telling at staff meetings and retreats was commonplace. It occurred so often that the staff added a regular staff meeting agenda item entitled "Updates" that allowed any interested staff person to share something that happened since that last meeting. One story that was retold several times when staff talked about writing new curriculum or instructional materials had to do with never knowing how much detail to include in the instructions. The story was first told by one instructor who had been working with a small group of students on some career exploration activities. She said she asked each student to go home and interview one person 
about his/her job. They were to come back the next day to tell the rest of the group what they learned form that person.

The next day the instructor began the group by asking them to tell who they interviewed and what the job was. When she got to one young man, she said, "George, who did you interview?" George said, "My father." The instructor hesitated a moment and said, "But your father is dead." George looked puzzled and said, "Did we have to interview someone who is alive?" The instructor would end the story by saying, "You just never know how specific you need to be when assigning work!"

To this researcher, the humor between staff and students plays several roles. One is to communicate a happiness to be a part of the program. The participants seem genuinely pleased to be where they are, and as researchers such as Wehlage (1983) point out, it is very important that both teachers and students choose to be in the alternative program, rather than placed there.

Second, the humor between students and staff communicates acceptance. The staff and students seem comfortable with each other and treat each other with a naturalness that includes humor and teasing. Gross (1990) reports acceptance and respect of students as vital for successful alternative schools and teachers. It seems humor can communicate a togetherness when it is shared humor and not derogatory.

The staff and students of Tri City Alternative Program are creating a complex microculture as they interact daily in the context of the program. They are developing expectations and competencies that are communicated clearly with caring 
and humor in a way that allows students to succeed in an educational program. The next chapter will propose some larger generalizations and future directions building on this study of alternative program microculture. 


\section{CHAPTER VI}

\section{CONCLUSIONS AND FUTURE DIRECTIONS}

The purpose of Chapters IV and V was to provide enough descriptive data to answer the question, "What appears to be the distinguishing microculture created by the participants of the alternative school?" The description pointed out the elements of the structure and the interaction patterns that define the microculture. From those chapters, a reader would understand the cultural elements of Tri City Alternative Program and would be able to compare that understanding against descriptions of other alternative education programs.

Erickson and Wilson maintain that all research of the same nature as this study seeks to answer the general question, "What's happening here, specifically?" (1982, p.40). It is a deceptively simple question because

First, everyday life (because of its familiarity and because of its contradictions) is largely invisible to us-we do not realize the patterns in it. Second, everyday life is organized in slightly differing ways from one setting to the next. Often these objectively small differences of pattern and meaning can make a big difference in the subjective reality and qualitative character of social relations in the setting. These differences across settings can affect such matters as program implementation. Third, because many of the patterns are outside conscious awareness of the actors in the setting and because many of the patterns are constructed around distinctions of meaning attached to slight differences in amount (such as the measurable difference between "not too loud" and "too loud"), description and analysis of specific local details is necessary. The widely ranging view or measurement by general categories may miss subtle features that have 
important consequences for causation or for the underlying structure of patterns and ecological relations in the local setting (Erickson and Wilson, 1982, p.40).

Even the participants of Tri City Alternative Program benefit from this type of study. They can more clearly see their actions and intentions, determine the impact of their interactions, and decide how to best serve students.

In this chapter, I will move away from the specific data of the study and look at the conclusions and recommendations I would draw from the experience of this research. There are three areas of discussion: the synchronization of cultural context and interaction, the need for additional cultural studies of dropouts, and the potential benefit of participation observational research in education.

\section{THE SYNCHRONIZATION OF CULTURAL CONTEXT AND INTERACTIONS}

As shown in the description of the Tri City Alternative microculture, the context (structure) of the program and the interactions (behaviors) of the participants reflected and affected each other. This was not by chance; it indicates a definite intent on the staff's part. The staff had numerous discussions clarifying what the purpose of program elements was, and once an agreement was reached, the staff reinforced that value in action and environment.

I am labeling this working together of the context and actions "synchronization". For example, when the staff decided to value communication, their first actions were providing opportunities such as field trips and program tours. 
They then affected the context by displaying student work and building group work into the program schedule.

There seem to be several keys to developing the synchronization of context and action that build successful programs. First, the decisions are value based. An underlying assumption of alternative education is that there are multitple ways to organize schools and deliver education. How the program staff decides to deliver their specific program must have a value base that all know and support. That way, the value can be reinforced throughout the program.

Second, when the context and actions are synchronized, the impact is multiplied. Every staff member reinforces the same value, and the environment communicates the message. Students' and staff's actions are defined through context and interactions. Consistent behavior and language results.

Lastly, every component (context or interaction) must fit the whole program. Alternative programs can be developed around different time structures, teacher roles, learning environments, instructional modes, or teaching outcomes. However the components are designed, there must be consistency of value for the program to be successful. In looking at how the staff built a relationship between context and interactions, there was a consistent connection between the elements. Visually, this could be represented as wheels with matching cogs. Each interaction is matched or supported by the context. The cogs match and the program "flows". Figure 6 shows this relationship. 


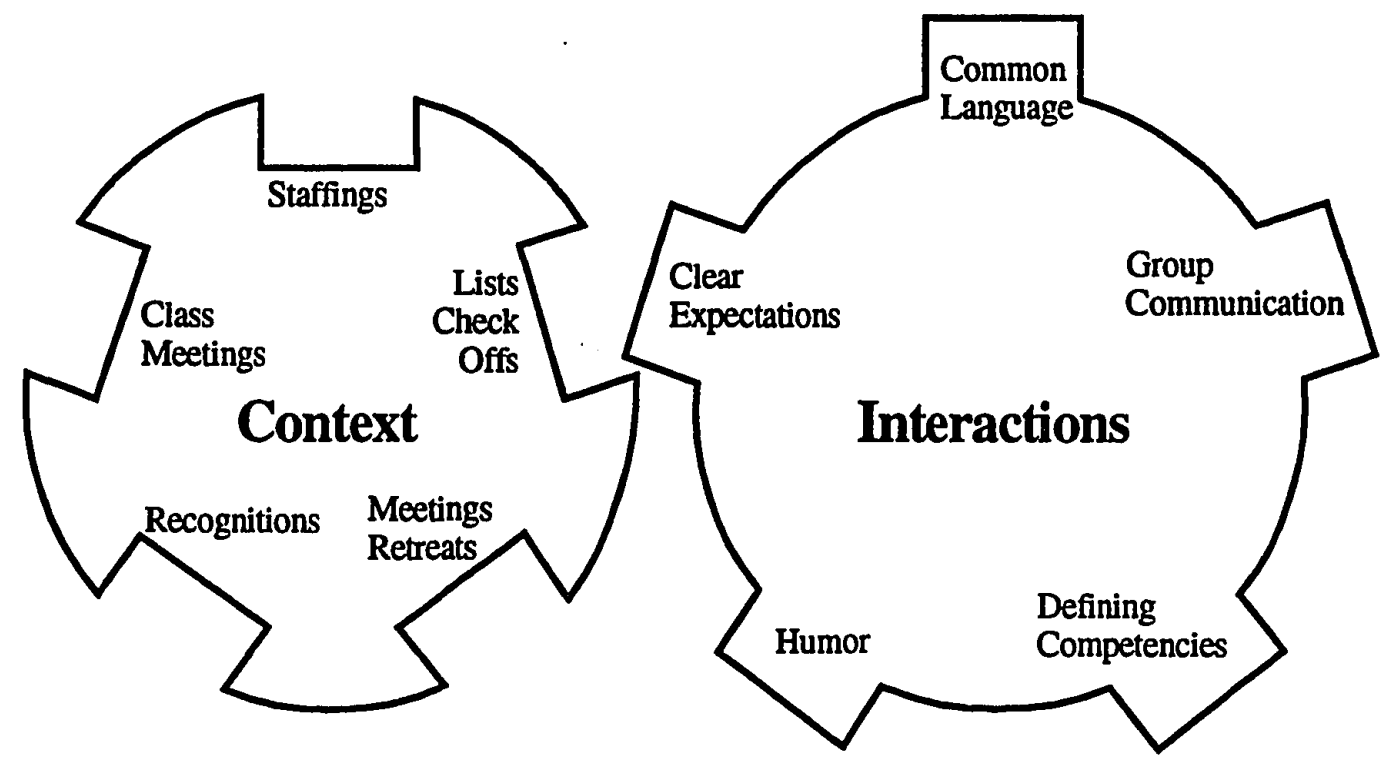

Figure 6. Synchronization model. 
When a program has a microculture in which context and behaviors are synchronized, there is less likelihood of confusion or contradiction. Students and staff benefit from consistency among the formal and informal elements of the program. I would recommend that this view of synchronization be tested when designing new programs or planning program refinements. The program participants could see if there is support for program changes in the context and in the interactions. Program evaluators might be able to visually map out the program elements and their relationships. One test for the model might be to look at program components that are not having the impact anticipated and ask, "Is there a lack of connection between context and action?" For example, do students relate that expectations are unclear even though teachers have extensive scope and sequence charts? Do the staff state they value all types of communication but only provide for the types found on standardized tests?

\section{ADDITIONAL CULTURAL STUDIES OF DROPOUTS}

The growing body of research that looks at schools and the students in them through a cultural perspective should be better developed and expanded. Sarason has pointed out that "both the insider and outsider show an amazing degree of ignorance about the culture of school" (Sarason, 1971, p.2). He maintains that most professionals are more acquainted with individual behavior and learning and are ill equipped to look at group and cultural aspects of schooling. This seems particularly telling since our schools are organized around groups of students. If educators and 
researchers incorporated more of a cultural view, they should be better able to make decisions about schools, since "culture defines the permissible ways in which goals and problems will be approached" (Sarason, 1971, p.12). For example, questions about changes in instructional delivery could be considered in light of the cultural elements that support or conflict with the new strategy.

In a recently published book, Michelle Fine painted a picture of a high school that maintains "layers of systemic, widespread school failure" (1991, p.7). She expressed surprise at the lack of attention paid to the cultural elements, the real life elements of schools. There was a reluctance on the part of the educators to discuss dropouts or related social issues. She labeled this as a "silencing" function of the school. It had real consequences for the issues surrounding dropouts because "both educators and many youth themselves viewed these events as individual "choices" or due to personal inadequacies. Perhaps this is the most compelling consequence of institutionalized silencing. When the policies and practices of purging are rendered invisible, no one but the adolescent is held to blame." (Fine, 1991. p.82)

A cultural perspective requires researchers to name and study those elements that are hidden. It implies that the individual be studied in a setting that is understood to have influence on that individual. Dropouts have had too little of this type of attention, this type of research. The result has been decriptions of dropouts without an understanding of the interrelationships between student characteristics and school environments. 
In one study reporting the mixed results of a less than successful alternative program, the researchers (Kaczyski, Bedics, and Slattery, 1990, pp.7-9) observed "organizational confusion", failure "to adjust their expectations", "terrible disappointment", and "problems working with the non-traditional students". These problems existed even though the program was modeled after a national model program and displayed the characteristics of successful programs: small size, experiential learning, work experience. The authors of the study suggested improvements of more staff meeting time, more training in values and staff roles, and more student input. All of these seem related to the culture and aimed at getting the program elements supportive of the culture. They point to the missing link between lists of characteristics and implementing successful programs. Additional research is needed to better understand total programs, not just characteristics. This study added to the understanding of total programs by specifically describing how Tri City characteristics are enacted.

\section{BENEFIT OF PARTICIPANT OBSERVATIONAL RESEARCH}

Participant observational research seems to be a tool that could be particularly beneficial to teachers and students. People in schools can use it as a mirror to hold up to themselves and their actions. Feer (1975) trained high school students in some qualitative research tools: observing, interviewing, interpreting. The students then studied the behaviors of students in their school. It seems this approach would have numerous applications with youth. High risk youth often lack perspective to judge 
their actions. Perhaps, having tools that help them put behaviors into context would lead to better self understanding or to increased understanding about behavioral or cultural options.

Teachers could be taught how to be a participant observer in their own classrooms. They would learn that there is very little about the structure or interaction of the classroom that is absolute. They could begin to view the context and behaviors as options along a range that the participants develop. Classrooms would be seen as social settings that can change.

Teachers using participant observer techniques might feel more empowered because they would become aware of how individuals affect settings and how settings affect individuals. They would see how small changes in their behavior or the classroom environment could result in signficant educational changes. They would see the power and influence they could have upon students' lives. This would be a counterbalance to the disempowered teachers Fine (1991) observed. She found teachers so out of touch with students' lives, so alienated from students and staff that their actions and words conveyed a lack of value for themselves and their students.

Goodlad (1984) found a contradiction between what teachers said they were interested in fostering in their classrooms and the practices they employed. Teachers said they were interested in the personal lives of students, but they avoided contact with personal issues. They said they were interested in group skills, but they maintained a system of lecturing so that control would be exercised over students. 
Teachers must find a way to reflect on their intent and their actions; participant observational techniques might be the vehicle for teachers to look carefully at themselves and be "able to make connections that are not obvious and to ask difficult questions" (Bellah, Madsen, et al, 1985, p.301).

This study of Tri City Alternative Program is a snapshot in time of one program. In that way it illustrates a shortcoming of decriptive research for programs and "microcultures are not static" (Erickson, 1986, p.130). On the other hand, it gives the reader an understanding they could not have acquired any other way. Readers have a glimpse of how a group of people can deliberately create a microculture that states expectations, pays attention to culture, demonstrates caring, defines competence, and creates laughter.

After the experience of conducting this study and working in Tri City Alternative Program, I strongly believe:

1. Attention to any program's culture is the most important aspect to its success. Teaching skills can happen in a variety of ways: with computers, books, tutors. What is important is that students and staff have a consistency between the social and academic portions of their lives, that the context and intercations reinforce each other, and that the participants are aware of their own role in developing the culture. 2. There needs to be more research about the teachers who are uncomfortable with the traditional school organization. The teachers in Tri City had taught in public schools, but they are now choosing to teach in the alternative school. There are teachers in tradtional schools who create very unique microcultures in their 
clasrooms. To what are these teachers paying attention? Are there certain factors related to their developing unique microcultures?

3. Microcultures do change with individuals. Tri City Alternative Program can lose its strong attention to culture with instructors who do not understand its importance. There is fine line between passing on the culture and stifling innovation. This is the callenge for the staff as new members join the program.

I have suggested some further applications of participant observational research, called for more study of dropouts, and proposed a visual model of context and interaction sychronization. However, more importantly, I have been changed by conducting this research. I no longer just observe behavior; I look for meaning and patterns more extensively than I ever did. I ask what role or purpose patterns of behavior have for individuals. I am convinced that when educators are "properly informed by an awareness of culture, tough decisions may contribute to an institution's sense of purpose and identity" (Tierney, 1988, p.5).

As educators are faced with educational reform efforts, they may well ask how this type of study could help inform them how to participate in developing cultures or microcultures that are nurturing, supportive, and productive. The first response I would give them would be to say, "Look to the participants, staff and students, for the answers." It is the participants themselves who develop and live microcultures. Outsiders do not impose or dictate microcultures.

The second recommendation I would make would be to insure that reform efforts do not become too prescriptive or narrow. One lesson of this study is that 
teachers can make big differences in classrooms by paying attention to the cultural aspects of the situation. This view can empower teachers to be sensitive to the variety of options available to them as they live their classroom lives.

Finally, I would challenge educators to discuss some school practices that might not be conducive to developing healthy microcultures. Those practices might include rotating principals and teachers on short time lines, eliminating time for teachers to interact with each other, employing only outsiders to recommend improvements. 


\section{REFERENCES}

Abraham, W. Motivating the Underachiever. Tempe, Arizona: Arizona Educational Informal System, 1977.

Apple, M.W. "Ideology, Reproduction, and Educational Reform." Comparative Educational Review, 22, No. 3 (1978), pp.367-387.

Bellah, R.N., Madsen, R., Sullivan, W.M., Swidler, A., and Tipton, S.M. Habits of the Heart: Individualism and Commitment in American Life. San Francisco: Harper and Row Publishers, 1985.

Carnegie Foundation for the Advancement of Teaching. Campus Life: In Search of Community. New Jersey: Princeton University Press, 1990.

Catterall, J.S. "A Review of Selected Data and Research on School Dropouts: Evidence of Longitudinal Processes Leading to School Attrition." The Urban Educator, (Spring/Summer), 1987, pp.23-50.

Conrath, J. "Ten Rules for Reducing Your Dropout Rate." The Executive Educator, 8, No.7 (1986), pp.24-25.

Cusick, P.A. Inside High School: The Student's World. San Francisco: Holt, Rinehart and Winston, 1973.

Erickson, F. AERA Winter Training Institute. Orlando, Florida, Feb. 1986.

Erickson, F. "Qualitative Methods in Research on Teaching." In Handbook of Research on Teaching. Ed. Wittrock. New York: MacMillan Publishing Co., 1986, pp.119-161.

Erickson, F. "School Literacy, Reasoning, and Civility: An Anthropologist's Perspective." Review of Educational Research 54 (Winter, 1984), pp.525-546.

Erickson, F. and Mohatt, G. "Cultural Organization of Participation Structures in Two Classrooms of Indian Students." Doing the Ethnography of Schooling, San Francisco: Holt, Rinehart and Winston, 1982, pp.133-174. 
Erickson, F. and Wilson, J. Sights and Sounds of Life in Schools: A Resource Guide to Film and Videotape for Research and Education. Michigan State University: The Institute for Research on Teaching, Research Series No. 125, 1982.

Feer, M. "Informant-Ethnographers in the Study of Schools." Human Organization, 34, No.2 (1975), pp.157-162.

Fetterman, D.M., ed. Ethnography in Educational Evaluation. Beverly Hills: Sage Publications, 1984.

Fine, M. Framing Dropouts: Notes on the Politics of an Urban Public High School. Albany, New York: State University of New York Press, 1991.

Firestone, W.A. "Meaning in Method: The Rhetoric of Quantitative and Qualitative Research." Educational Researcher, 16, No.7, (1987), pp.16-21.

Frymier, J. "Children Who Hurt, Children Who Fail." Phi Delta Kappan, November, 1992, pp.257-259.

Frymier, J. and Gansneder, B. "The Phi Delta Kappa Study of Students at Risk." Phi Delta Kappan, October, 1989, pp.142-146.

Glaser, B.G. and Straussk, A.L. The Discovery of Grounded Theory--Strategies for Qualitative Research. Chicago: Aldine Publishing Co., 1967.

Glasser, W. Schools Without Failure. San Francisco: Harper and Row Publishers, 1969.

Goodlad, J.I. A Place Called School. San Francisco: McGraw-Hill Book Co., 1984.

Green, J.W. and Leigh, J.W. "Teaching Ethnographic Methods to Social Service Workers." Practicing Anthropology, 11, No.3, (1989), pp.5-10.

Green, K.R. and Baker, A. Promising Practices for High-Risk Youth in the Northwest Region: Initial Search. Portland, Or.: Northwest Regional Eduational Laboratory, 1986.

Gross, B. "Here Dropouts Drop In - And Stay!" Phi Delta Kappan, April, 1990, pp.625-627.

Howe, K. and Eisenhart, M. "Standards for Qualitative (and Quantative) Research: A Proglegomenon." Educationai Researcher, 19, No.4 (1990), pp.2-9. 
Kaczynski, D.J., Bedics, R.A., and Slattery, K.D. "A Qualitative Study of a Community College Program for High School Dropouts." Pensacola, Florida: Pensacola Junior College, 1990 (A paper presented at the annual meeting of the American Educational Research Association, Boston, Massachusetts, April, 1990).

Kempner, K. "Faculty Culture in the Community College: Facilitating or Hindering Learning?" The Review of Higher Education, 13, No.2 (1990), pp.215-235.

Kirsch, I. and Jungeblut, A. Literacy Profiles of America's Young Adults. Princeton, New Jersey: Educational Testing Service, 1986.

Lazarus, B.B. Practical Reasoning and Observation: A Second-Grade Teacher Refers Children for Special Education Services. Ann Arbor, Michigan: University Microfilms International, 1985.

Levin, H.M. The Costs to the Nation of Inadequate Education. Washington, D.C.: U.S. Government Printing Office, 1986.

Lightfoot, S.L. The Good High School. New York: Basic Books Inc., 1983.

London, H.B. The Culture of a Community College. New York: Praeger Publishers, 1978.

Mann, D. "Can We Help Dropouts: Thinking About the Undouble." Teachers College Record, 87, No. 3 (1986) pp.307-323.

Mann, D. Chasing the American Dream. New York: Community Service Society, 1980.

Mann, D. Oregon Alternative Education Association conference Keynote. Portland, Oregon, October, 1987.

National Education Goals Panel, The National Education Goals Report 1991. Washington, D.C.: U.S. Government Printing Office, 1991.

Oregon Department of Education, "A Study of Oregon's Early School Leavers Executive Summary." Salem, Oregon: Oregon Department of Education, 1987.

Oregon Department of Education, Alternative Education: A Roster of Programs. Salem, Oregon: Oregon Department of Education, 1991. 
Oregon Department of Education, "High School Dropout Rate Down Slightly." Education First, Salem, Oregon: Oregon Department of Education, September, 1992, pp.1-2.

Oregon Department of Education, "School Reform Update: Task Forces Present Proposals for Next Stage of Improvement." Education First, Salem, Oregon: Oregon Department of Education, October, 1992, pp.5-8.

Oregon Office of Community College Services,"The Community College Response to Educational Reform." Salem, Oregon: Oregon Office of Community College Services, October, 1992.

Oregon Progress Board, "Human Investment Partnership: Achieving Benchmarks for Exceptional People." Salem, Oregon: Oregon Progress Board, November, 1991.

Oregon Youth Coordinating Council, Model Programs. Salem, Oregon: Oregon Department of Education, 1985.

Portland State University, "Evaluation: Partnership for Youth Success Project." Portland, Oregon: Portland State University, 1986.

Rumberger, R.W. "High School Dropouts: A Review of the Issues and Evidence." Review of Educational Research, 57, No.2 (1987), pp.101-121.

Sarason, S.B. The Culture of the School and the Problem of Change. Boston: Allyn and Bacon, Inc., 1971.

Schmuck, R. "The School Organization", The Social Psychology of School Learning. New York: Academic Press, 1979.

Spindler, G.D. Education and Culture. San Francisco: Holt, Rinehart and Winston, 1963.

Spindler, G.D. "General Introduction", In Doing the Ethnography of Schooling. San Francisco: Holt, Rinehart and Winston, 1982, pp.1-13.

Spring, J. The Sorting Machine: National Educational Policy Since 1945. New York: David McKay Co.Inc., 1976.

Tierney, W.G. "Organizational Culture in Higher Education: Defining the Essentials." Journal of Higher Education, 59, No.1 (1988), pp.2-20. 
Toles, T., Schultz, E.M., and Rice, W.K. "A Study of Variation in Dropout Rates Attributable to Effects of high Schools." Metropolitan Education. 2 (1986), pp.30-38.

U.S. Department of Commerce (Bureau of the Census), School Enrollment - Social and Economic Characteristics of Students: October 1990. Washington, D.C.: U.S. Government Printing Office, 1992.

U.S. Department of Education, State Education Statistics. Washington, D.C.: U.S. Department of Education, 1986.

U.S. General Accounting Office, School Dropouts: Survey of Local Programs, Washington, D.C.: General Accounting Office, 1987.

Wehlage, G.G. Effective Programs for the Marginal High School Student. Bloomington, Indiana: Phi Delta Kappa Foundation, 1983.

Wehlage, G.G. and Rutter, R.A. "Dropping Out: How Much Do Schools Contribute to the Problem?" Teachers College Record 87 (1986), pp.374-392.

Weis,L. Between Two Worlds, Boston: Routledge \& Kegan Paul, 1985.

Willett, J.B. and Singer, J.D. "From Whether to When: New Methods for Studying Student Dropout and Teacher Attrition." Review of Educational Research 61, No.4 (1991), pp.407-450.

Willis, P. Learning to Labor: How Working Class Kids Get Working Class Jobs. New York: Columbia University Press, 1977.

Wolcott, H.F. "Criteria for an Ethnographic Approach to Research in Schools," Human Organization, 34, No.2 (1975), pp.111-127.

Wolcott, H.F. "Ethnographers Sans Ethnography: The Evaluation Compromise." In Ethnography in Educational Evaluation. Beverly Hills: Sage Publications, 1984, pp.177-210.

Wolcott, H.F. "Models and Monitors: Educator Adaptations of the Ethnographic Innovation," In Doing the Ethnography of Schooling. San Francisco: Holt, Rinehart and Winston, 1982, pp.68-95.

Yin, R.K. Case Study Research: Design and Methods. Beverly Hills: Sage Publications, 1984. 
APPENDIX A

DAILY GOAL SHEET SAMPLE 


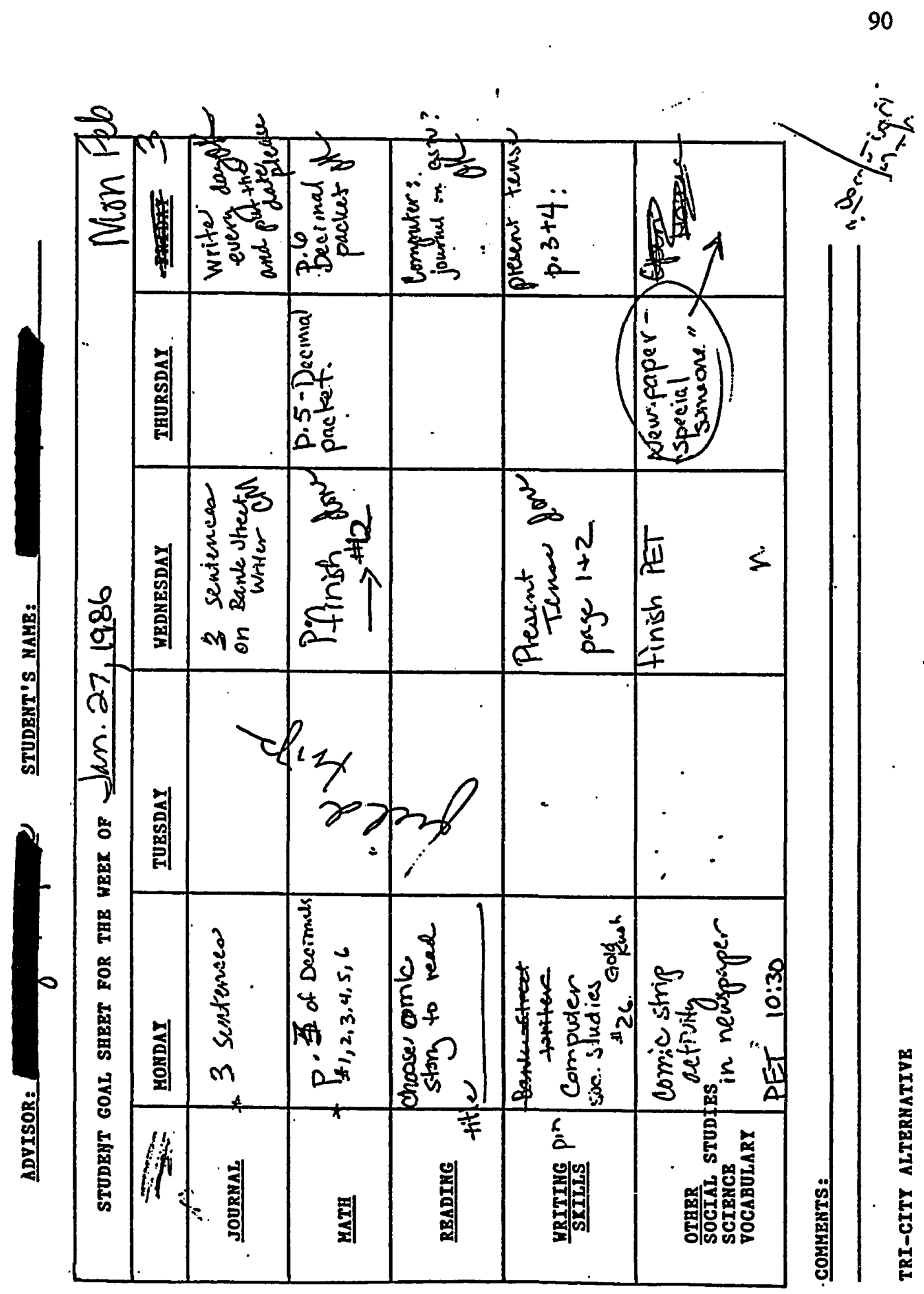


APPENDIX B

WEEKLY GOAL SHEET SAMPLE 


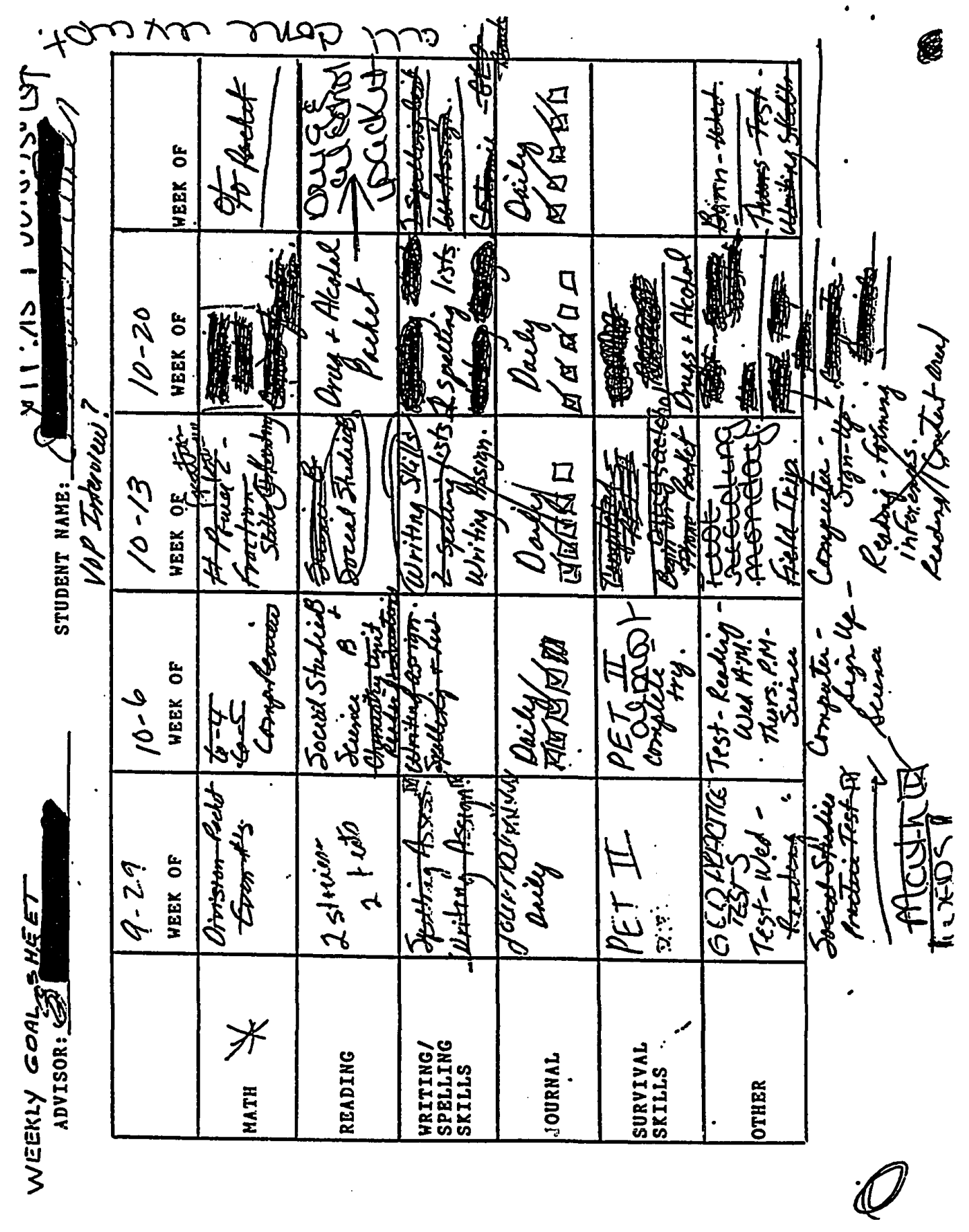


APPENDIX C

SENTENCE COMPLETION SAMPLE 


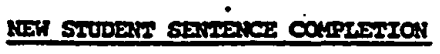

Complete the following sentewcess

a saturany I uke to sper $\alpha$ tine, with

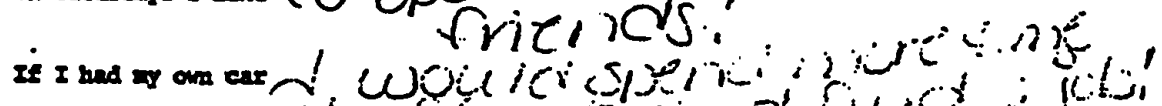

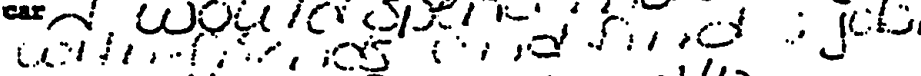

I soel beat then people ask me for $17 x(p \omega / 1)$ personat pictiriras

a racution I uke to" o placks die never beth

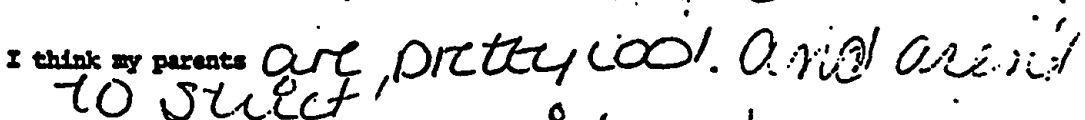
many people don't agroe wath nout vieleâ

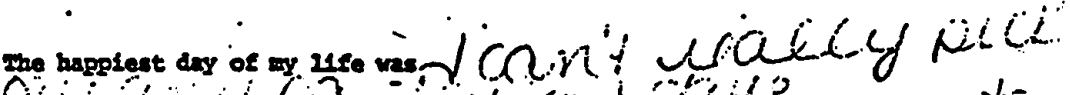

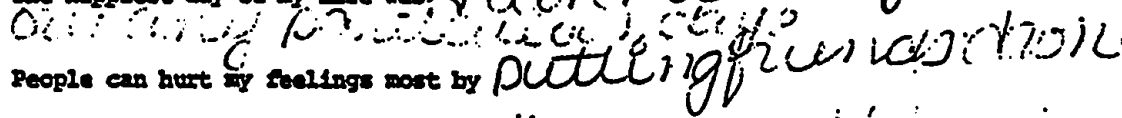

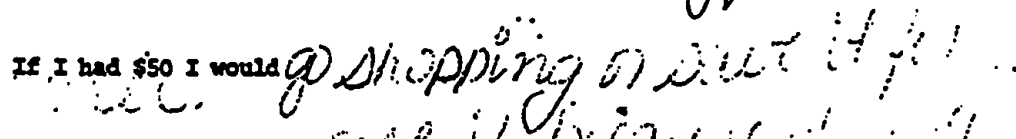

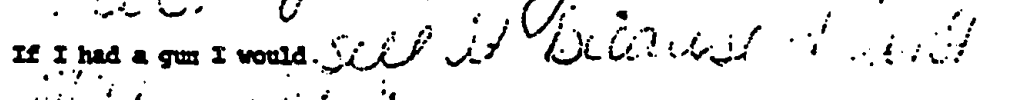

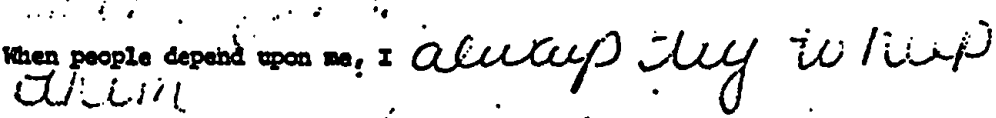

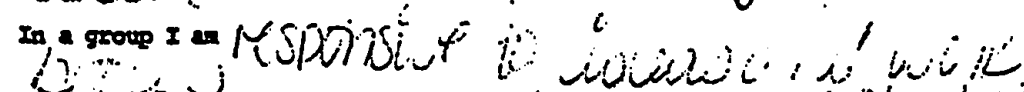

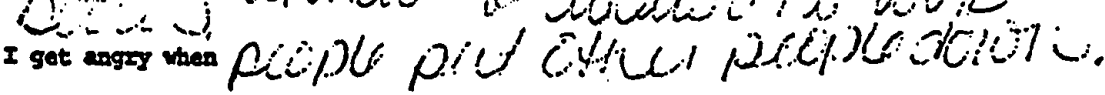

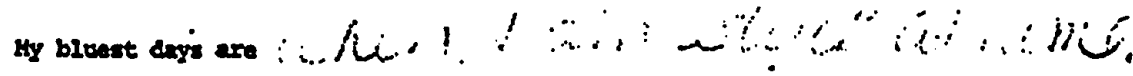

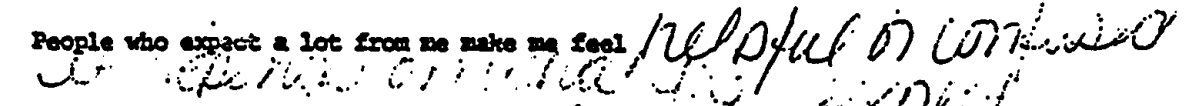

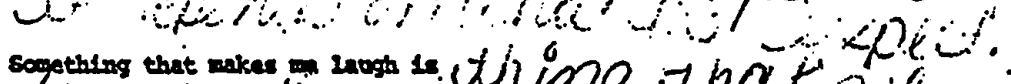

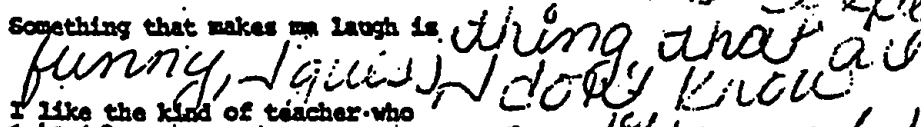

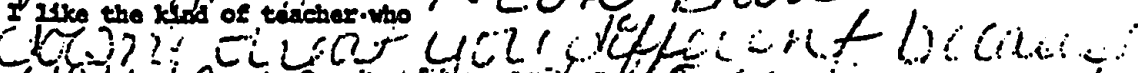

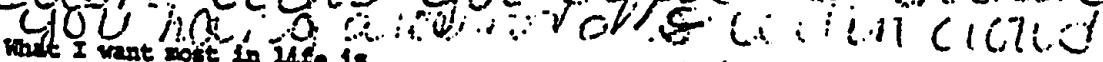
$\therefore$. : 
APPENDIX D

INTERVIEW FORM SAMPLE 


\section{Leveir cecouds teom Tivety Olackesser. VOCATIONAL OPTIONS CENTER STUDENT INTERVIEW/INTAKE}

1. Entry Date readen 6th math sid

Exit Date Interviewer Identification: ADDRESS DATE

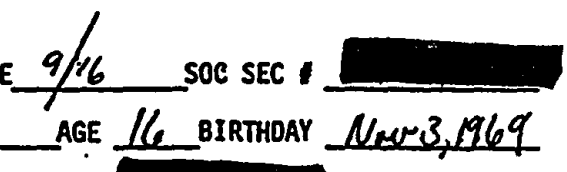
PARENTS: HOHE PHONE

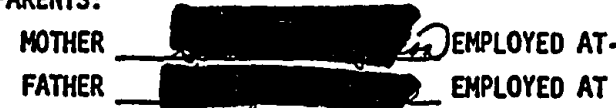

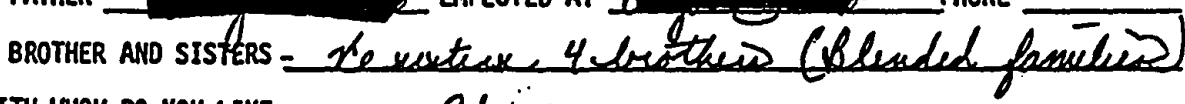
WITH WHOM DO YOU LIVE aboive.

TRANSPORTATION AVAILABLE FOR MORK ferew

2. School Nucdiren

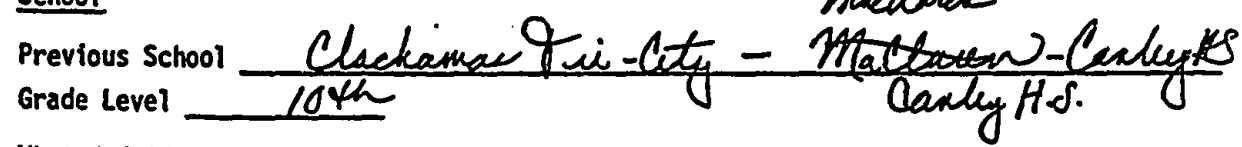
What do/did you like best about school? = What do/did you not like about schools = Stasecture - Nuestaleatol Does/did schoor work ever give you trouble? Explain. -Writisi dyffecelto feadinglese Math What kind of special help did you get with these problems?

\section{Atlesuatrif Selool}

Did teachers or principals ever give you any trouble?

Did you ever give teachers or principals any trouble?

91 daus in Anatreatment - at Madeur 
2. School continued:

What kind of help did/do you get to wark sout these troubles?

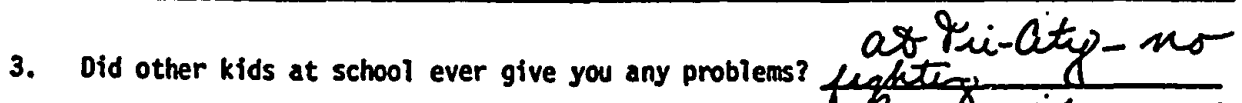

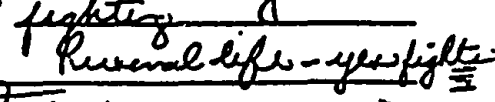

Did you ever have a habit of skipping school?
What about school made you want to skip?

Doldid drugs or alcohol contribute to your problems at home or school? Zevet Do/did drugs or alcohol contribute to Gour problems at home or school? 2ueat

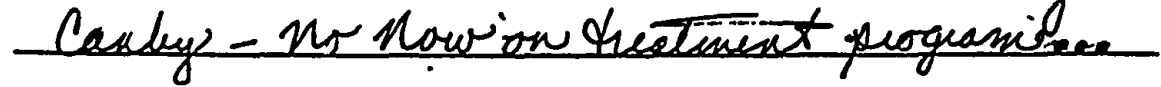

4. Work $\approx$

Have you ever had a job? Explain (what type/how long) Pruste faestey and

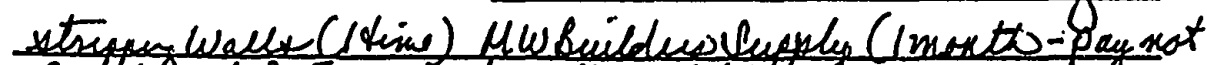

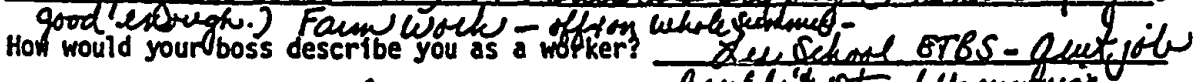

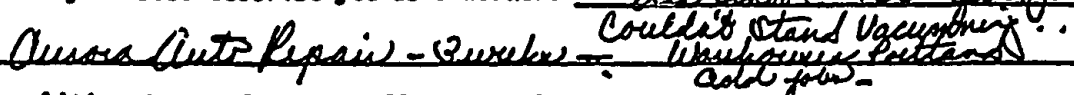
What qualities do you feel you offer an employer?

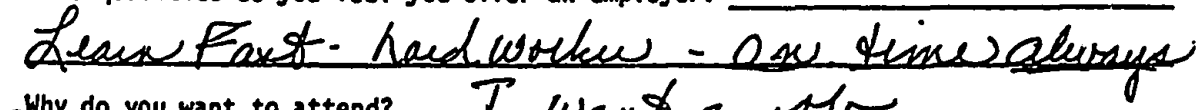
-Why do you want to attend? I wases a

- What do you want to accomplish while you're here? fefilex) to kespe ejw.

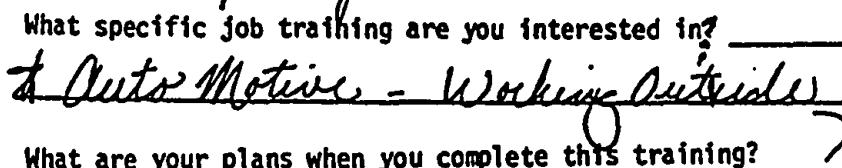
What are your plans when you complete this training? COMMUNITY COLLEGE SPECIAL TRAINING 4-YEAR COLLEGE

EMPLOYMENT MILITARY BACK TO HIGH SCHOOL 
4. Hork continued:

What are your career goals?

Pechereis

Why should I choose you to come to this school? Nedests ande Heese

What would you like to ask me about the training and classes?

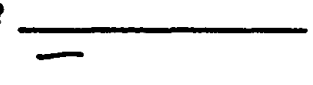

5. Leisure

What do you like to do for fun? Wrey dw Matricyele-Redin

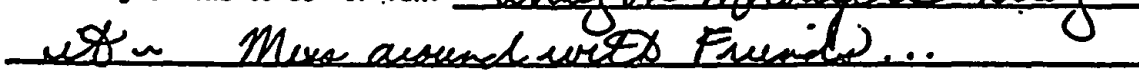

What are your interests/hobbies?

6. Learning Style

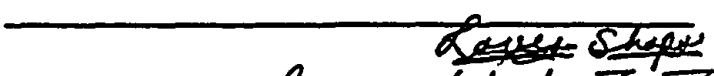

In what kind of situations do you learn best?

Noisy place Quiet Place

been in Wooder IF metax.

Alone $C$ Large Group Discussions weldi sucllongent.

Small Group Discussions Individualized Instruction

Lectures Conferences

What are/were your favorite subjects? Meted fale.

What were/are the hardest things for you to do in school? be lacgegroupe Take Tests Do Homework Attend Class s1t and Listen Meet Deadlines follow Rules Reading Math

Other 
99

Center Overview:

Selection Process

Attendance Policy

Drug/Behavior Policy

Program Structure (indiv. subj, journal, survival skills)

Hours/Break Policy

Advisor Contract

Center Clean Up

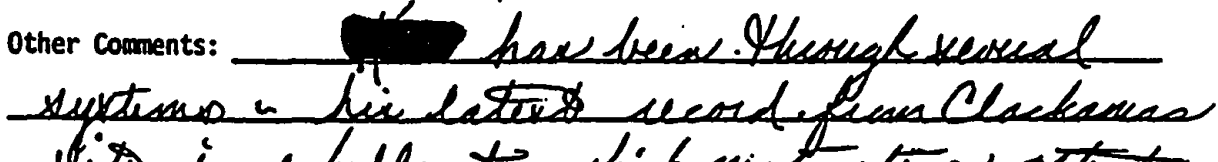

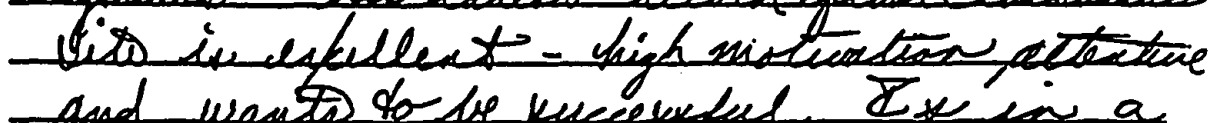

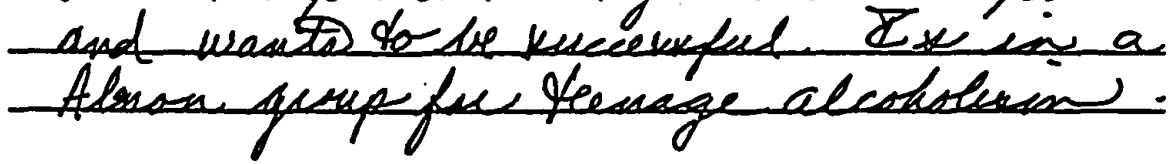

Things of be aware of

\#1- Pug q alcohol Pesters

\# 2-Quits whin the situate r.

sumo boning a deva's

meet his rede. 
APPENDIX E

CURRICULUM CHECKLIST SAMPLE 


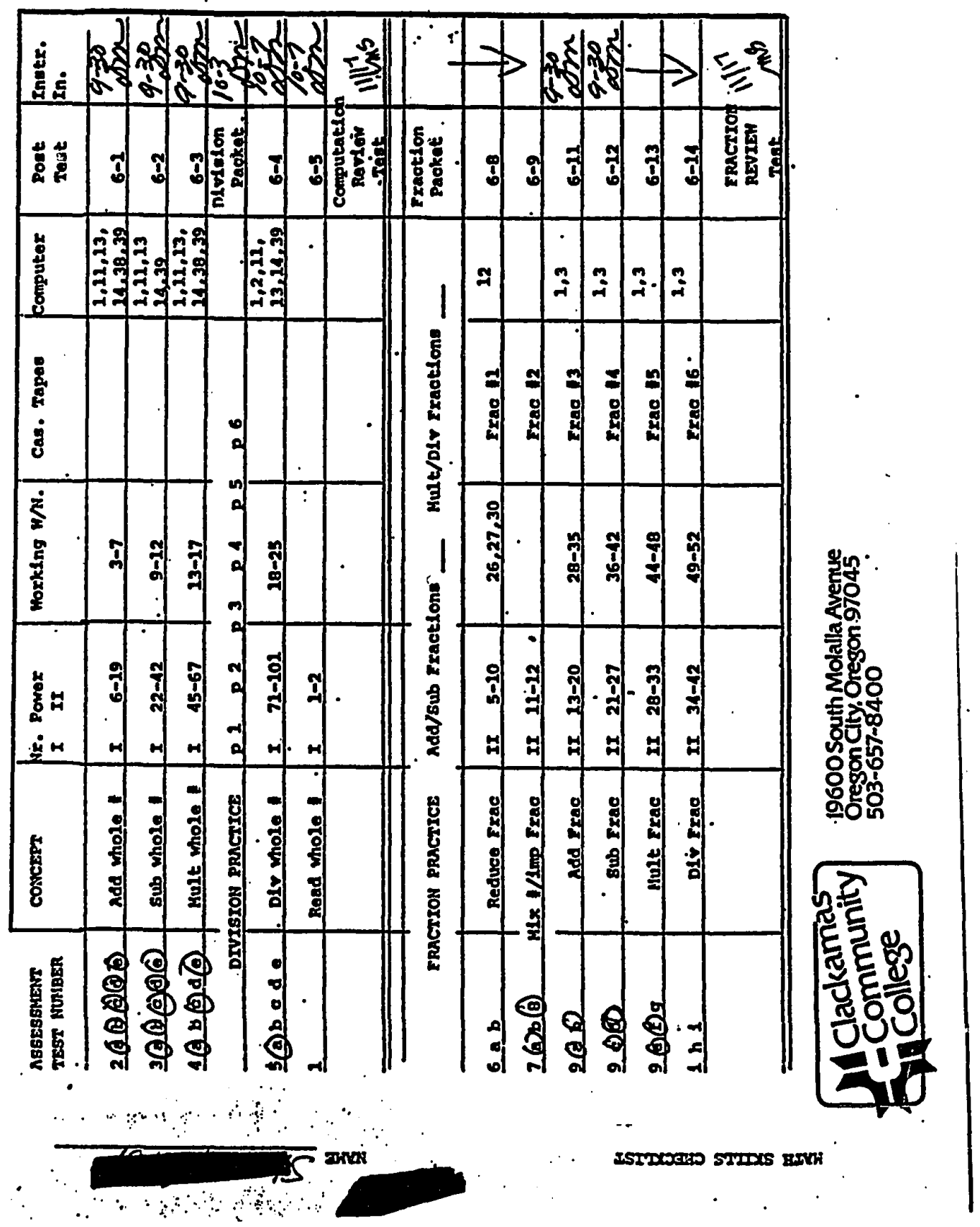




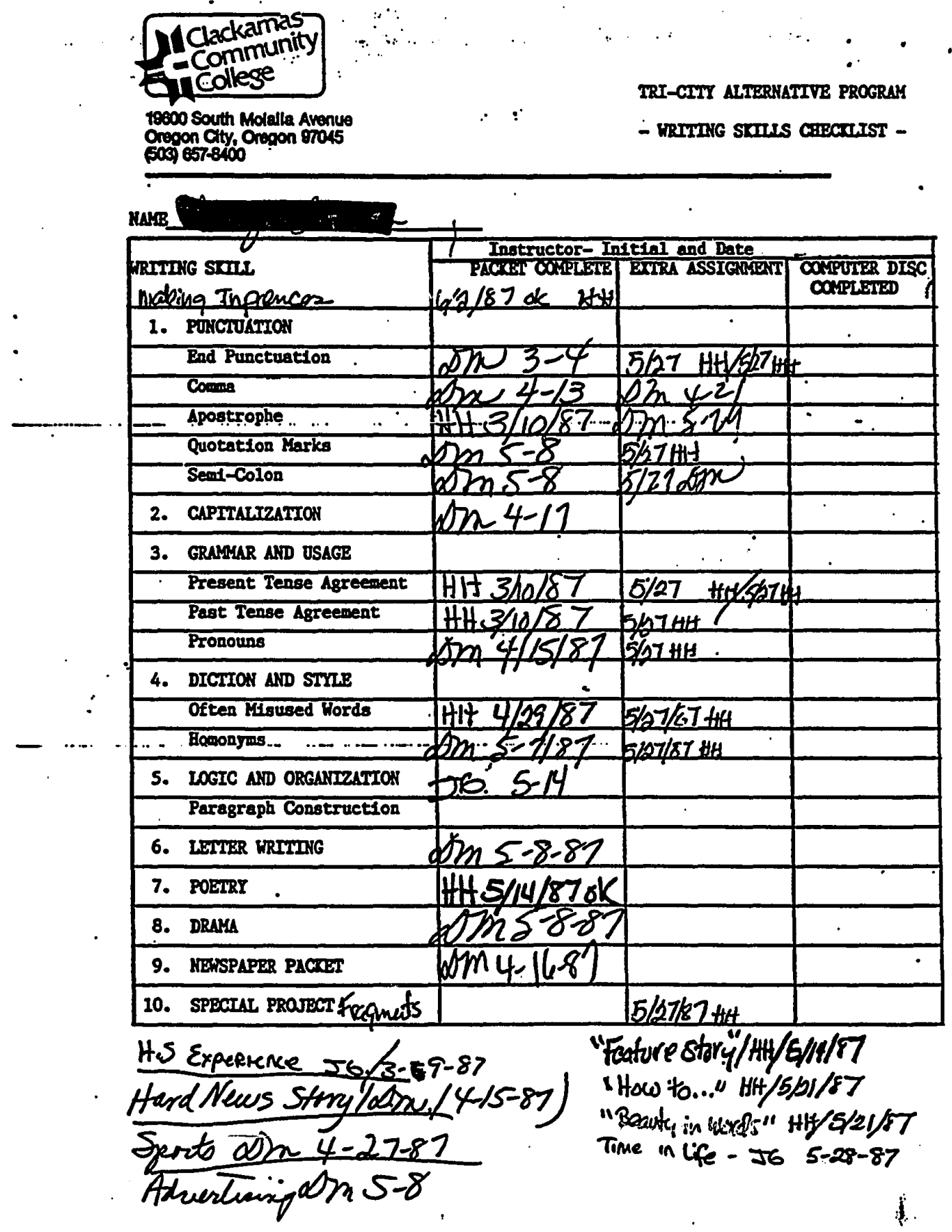

